\title{
Determinantes de la política de dividendos: evidencia del mercado latinoamericano (2012-2018)
}

\author{
Determinants of dividend policy: Evidence \\ from the Latin American market (2012-2018)
}

Felipe Carrasco-Tamayo* Mauricio Avellaneda-Hortua*

* Magíster en Finanzas. Analista senior de riesgo de crédito corporativo, BLADEX [felipe. carrasco@uexternado.edu.co].

** Magíster en Finanzas. Docente investigador, Universidad Externado de Colombia [mauricio.avellaneda@uexternado.edu.co] [ORCID: 0000-0002-3912-8680].

Artículo recibido el 01 de febrero de 2020.

Aceptado el 01 de marzo de 2020.

Para citar este artículo:

Avellaneda Hortua, M. y Carrasco-Tamayo, F. (2020). Determinantes de la política de dividendos: evidencia del mercado latinoamericano (2012-2018). ODEON, 18, 161-203.

DOI: https://doi.org/10.18601/17941113.n18.05 


\section{Resumen}

En este artículo se estudian los determinantes de la política de dividendos del mercado latinoamericano, partiendo de investigaciones previas realizadas sobre empresas localizadas en España, Nigeria, Rumania, Estados Unidos y Emiratos Árabes. La investigación busca establecer cuáles fueron los determinantes de la política de dividendos de empresas latinas (de Colombia, México, Brasil, Chile, Perú y Panamá) para los periodos comprendidos entre 2012-2018. En línea con lo anterior, este estudio busca determinar la relación que tienen el apalancamiento, la rentabilidad, el tamaño, los impuestos, la liquidez, el riesgo, el domicilio y la industria de empresas del mercado latino con la política de dividendos que estas establecen. Finalmente, el estudio (a través de modelos econométricos) muestra evidencia de la relevancia que tiene la percepción del riesgo sobre la firma, para establecer la política de dividendos.

Palabras clave: dividendos; riesgo.

Clasificación JEL: G30, G39.

\section{Abstract}

This article studies the determinants of the dividend policy of the Latin American market, based on previous research carried out on companies located in Spain, Nigeria, Romania, the United States and the United Arab Emirates. The research seeks to establish what were the determinants of the dividend policy of Latin companies (from Colombia, Mexico, Brazil, Chile, Peru and Panama) for the periods between 2012-2018. In line with the above, this study seeks to determine the relationship that leverage, profitability, size, taxes, liquidity, risk, domicile and the industry of companies in the Latin market have with the dividend policy that they establish. Finally, the study (through econometric models) shows evidence of the relevance of risk perception on the firm, to establish the dividend policy.

Key words: Dividends; risk.

JEL classification: G30, G39.

\section{Introducción}

El objetivo principal de las empresas es la creación de valor para sus accionistas. Para esto, recaudan recursos a través de capital o endeudamiento que se destina a la compra de activos productivos por medio de los cuales generan 
flujos de caja sobre los que sus acreedores y accionistas tienen derecho. En el caso de los accionistas, la retribución de la firma se puede realizar vía ganancia de capital o a través de distribución de dividendos, esta última es la forma más común de remuneración existente.

Dada la importancia que los dividendos representan para los inversionistas, ya que esta es una de las principales fuentes de retorno de sus inversiones, la academia ha buscado dar respuesta a dos interrogantes ¿por qué las firmas reparten dividendos? y ¿cuáles son los principales determinantes que llevan a que las firmas paguen o no su dividendo anual? Sin embargo, no se ha alcanzado un consenso sobre estas incógnitas, como lo plantea Fisher (1976), quien concluye que no se puede saber de manera precisa cuáles son los determinantes que llevan a una entidad a pagar dividendos.

... en principio, a algunos inversionistas les gusta recibir dividendos sin importar la desventaja tributaria que esto representa, dado su necesidad de recibir un flujo de caja constante sin importar si su costo fiscal se bajó o no. Las empresas que han pagado dividendos en varios periodos de tiempo tienden a tener más inversionistas con estas características y eliminar los dividendos puede no ser favorable para ellos. (Damodaran, 2014, pp. 730-731)

Actualmente, los avances teóricos que se han llevado a cabo sobre este tema pueden agruparse en dos corrientes de pensamiento:

La primera corriente fue la explicada por Modigliani y Miller (1961), quienes plantean la irrelevancia en el pago de dividendos para la generación de valor de la firma y sobre la cual puede inferirse que no existen determinantes específicos para la política de dividendos.

La segunda corriente plantea que los dividendos tienen efectos (positivos o negativos) para los inversionistas ya que tienen injerencia sobre el valor de la firma como lo muestran Modigliani y Miller (1963), Fisher (1976), Bernheim (1990) y Damodaran (2014), entre otros.

De esta teoría se desprende una subrama que afirma que los dividendos tienen un impacto negativo para los inversionistas (como lo exponen Litzenberg y Ramaswamy, citados en Holder, Langrehr y Hexter, 1998), pues afectan el retorno que estos reciben de las compañías, producto de las altas tasas impositivas asociadas a este tipo de ganancia. De este planteamiento se deduce que el impuesto cobrado (tasa de retención al pago de dividendos) es el principal factor para la determinación de la política de repartición de dividendos de las firmas. 
La segunda posición de esta corriente académica plantea que el pago de dividendos agrega valor a la firma, de lo que se concluye que en una compañía existen ciertas determinantes (estructura de capital, impuestos, rentabilidad, asimetrías de información, etc.) que explican la determinación de la política de dividendos y que van en línea con lo planteado por varios autores (Fisher, 1976; Miller y Rock, 1985; Obradovich y Gill, 2013; Juma'h y Oliveras Pacheco, 2007; Amarjit, Nahum y Tibrewala, 2010; Cristea y Cristea, 2017).

Dada la discrepancia sobre los dividendos, diferentes investigadores como Vera (2007), Amarjit, Nahuman y Tibrewala (2010), Uwigbe, Jafaru y Anijesushola (2012), Cristea y Cristea (2017) y Mehta (2012) han buscado, a través de ejercicios empíricos, demostrar qué corriente de pensamientos es correcta y si es posible poder llegar a establecer cuáles son las determinantes de la política de repartición de dividendos de firmas ubicadas alrededor del mundo.

Siguiendo con lo mencionado en el párrafo anterior, si bien se han hecho aproximaciones teóricas a la problemática inicialmente planteada en diferentes países, no se hallaron investigaciones que se aplicaran al mercado latinoamericano, por lo cual en este trabajo se busca establecer si existen determinantes (apalancamiento, rentabilidad, riesgo, liquidez, tamaño, impuestos, entre otras) que expliquen la política de repartición dividendos de la empresas latinas y, en caso de que estos existan, poder determinar cuáles son los más relevantes. Para esto, se tomarán como referencia las investigaciones realizadas por Vera (2007), Amarjit, Nahum y Tibrewala (2010), Cristea y Cristea (2017), Uwigbe, Jafaru y Anijesushola (2012) y Mehta (2012), para las economías de España, Estados Unidos, Rumania, Nigeria y Emiratos Árabes respectivamente.

\section{Marco teórico}

Una de las primeras aproximaciones académicas realizadas al problema de por qué se reparten dividendos fue la presentada por Modigliani y Miller (1961) en su trabajo "Dividend policy, growth and the valuation of shares", donde a través de investigación (teórica) buscaron explicar cómo el pago de dividendos afectaba el valor que puede alcanzar una firma. En dicha investigación, los autores plantean un escenario de mercado perfecto ${ }^{1}$ en el cual existe un comportamiento

1 Mercado perfecto: no hay información asimétrica y ningún comprador o vendedor es lo suficientemente grande para distorsionar el mercado (Modigliani y Miller, 1961). 
racional por parte de los inversionistas ${ }^{2}$ y hay certeza sobre el comportamiento futuro de la inversión. Las conjeturas planteadas se centraban en determinar la relevancia de la política de dividendos para el valor de la firma, partiendo de la premisa de que entre mayor sea el valor del dividendo pagado por la firma, menor será la ganancia que obtendrá el inversionista en la apreciación (valorización) de las acciones (precio de la acción), es decir que el valor adicional que la compañía reparta en dividendos terminará reduciéndose del precio por acción de la firma en la misma proporción, lo que lleva a que para el inversionistas se vuelva irrelevante la política de dividendos que adopte la compañía, ya que siempre obtendrá el mismo retorno sea vía dividendos o vía ganancia de capital.

El precepto de irrelevancia planteado por Modigliani y Miller (1961) lleva a que pueda inferirse que, dada la insignificancia que tienen las políticas de repartición dividendos en la generación de valor de la firma, no existen características específicas (estructura de capital, tasa impositiva, preferencias del inversionista, etc.) que ayuden a determinar cómo una entidad establece su política de dividendos, dado que dependerá $100 \%$ del criterio de su administración la determinación del pago (este pago no es relevante).

Debido a que este planteamiento parte del escenario de un mercado perfecto, en donde no existe arbitraje ${ }^{3}$ (precepto que se considera errado ${ }^{4}$ ), los autores dan un alcance a su investigación a través de su publicación "Corporate income taxes and the cost of capital: A correction" (Modigliani y Miller, 1963), en donde determinan que el valor de una firma puede afectarse por el ahorro de impuesto que una compañía puede alcanzar dependiendo de su estructura de capital (apalancamiento). En línea con lo anterior, empezamos a ver que los impuestos pasan a ser una variable importante en la determinación del valor de la firma.

2 Comportamiento racional inversionistas: siempre busca la maximización de su riqueza (Modigliani y Miller, 1961).

3 En un mercado sin arbitraje, ningún activo que tenga características iguales puede tener diferencia en su precio, es decir, ninguna persona puede beneficiarse de errores de precios de activos en el mercado. Esto parte de la existencia de certeza total en el mercado, donde todos los miembros que participan en él conocen la rentabilidad de los activos (Modigliani y Miller, 1961).

4 En las prácticas de mercado no se tiene certeza total sobre los rendimientos de los activos. En este sentido, al existir asimetrías de información, los participantes del mercado pueden tener mayor o menor información sobre el comportamiento de un activo, lo que les permitiría realizar arbitraje sobre el precio futuro del mismo. 
Siguiendo esta conjetura sobre los impuestos, en la academia empezó a plantearse la pregunta: ¿cómo afecta la tasa impositiva a la política de repartición dividendos de una firma? De acuerdo con lo expuesto por Damodaran (2014), los planteamientos teóricos de mediados del siglo Xx empezaron a inferir que la repartición de dividendos no era positiva para los inversionistas debido a las altas tasas de retención (impuestos retenidos a los inversores) que tenían los ingresos por dividendos frente a las ganancias de capital que podía generar un inversionista al vender sus acciones. De acuerdo con lo expuesto por el autor, los inversionistas racionales buscan maximizar su utilidad, por lo cual prefieren maximizar el retorno de sus inversiones a través de la forma de liquidación (ganancia de capital o dividendos) más conveniente, la cual tiende a ser la opción de una menor tasa impositiva.

Otra corriente de pensamiento derivada de la teoría planteada por Modigliani y Miller (1963) fue la explicada por Miller y Rock (1985), donde los autores muestran cuál es el impacto que tiene el anuncio del pago de dividendos en el valor de la firma, partiendo del entendimiento de la existencia de asimetrías de información en el mercado (en este modelo se asume que la administración de las empresas mantiene mayor información sobre el desempeño financiero y económico de las firmas donde trabajan que el resto de los inversionistas del mercado). En esta aproximación teórica, los autores demuestran que la valuación de la empresa se afecta por la percepción que tienen los inversionistas frente a las señales que arroja la firma al mercado al realizar un pago de dividendos. Si analizamos esto, y en línea con lo expuesto por Damodaran (2014), se puede llegar a inferir que los pagos de dividendos terminaban siendo algo positivo para las firmas ya que la valoración de las empresas podría verse beneficiada por las percepciones de riesgo que tenía el mercado frente al pago de dividendos de las firmas.

A partir de lo revisado anteriormente, las teorías planteadas sobre los dividendos se pueden clasificar en dos grandes corrientes de pensamiento:

a. Los dividendos son irrelevantes para una firma, por lo cual no existen patrones de comportamiento que puedan explicar la razón de las políticas de repartición de dividendos de las compañías.

b. Los dividendos pueden afectar de manera positiva o negativa la valoración de una firma, por lo cual, la política de dividendos que acoja una compañía tiene relevancia para su valoración. En este escenario se podría inferir, entonces, que existen características comunes que podemos encontrar en las compañías que 
reparten dividendos y podría llegar a analizarse cuáles son los determinantes que explican el comportamiento en el pago de dividendos por parte de una entidad.

A partir de la segunda corriente de pensamiento, la academia empezó a desarrollar trabajos (aproximaciones empíricas y teóricas) buscando dar respuesta a la pregunta: ¿cuáles son los determinantes de la política de dividendos?

Uno de los primeros autores en desarrollar un planteamiento para responder a esta incógnita fue Fisher (1976), quien a través de una aproximación teórica buscó ver cómo diferentes variables explicaban el pago de dividendos de la firma. En línea con lo anterior, Fisher plantea posibles soluciones a la explicación del rompecabezas de los dividendos partiendo de información académica existente, sin realizar una aproximación cuantitativa al problema. En este trabajo Fisher, después de hacer un estudio sobre las diferentes corrientes académicas que habían investigado la determinación del pago de dividendos, estableció que las variables más significativas encontradas a lo largo de su investigación académica para explicar el pago de dividendos son:

a. Los impuestos (afectan directamente el retorno al inversionista).

b. La percepción del mercado, analizando cómo el comportamiento del precio de la acción respondía frente a la política de dividendos (respuesta del inversionista frente al precepto de riesgo retorno).

c. La percepción de los acreedores financieros.

d. La disponibilidad de caja, capacidad de reinversión de utilidades para financiamiento del crecimiento de la entidad (capacidad de contar con los recursos necesarios para realizar el pago de dividendos).

e. El comportamiento de los inversionistas, entre otras variables.

En este estudio, Fisher muestra cómo un inversionista preferirá que la tasa de dividendos de una firma sea más baja a medida que las tasas impositivas que graban a los dividendos sean mayores a aquellas que graban a la ganancia de capital.

En seguida, el autor analiza cómo el comportamiento de la gerencia influye a la hora de establecer la política de dividendos, ya que ambos agentes (accionistas y administración) utilizan los dividendos como un medio de transmisión de información al mercado sobre el futuro de la compañía, más puntualmente, como una señal positiva frente a los periodos por venir (perspectivas positivas del 
desarrollo de la firma). En este punto, Fisher resalta que la gerencia está enfocada, más que en la política de dividendos, en la forma en que varía la misma de un año a otro ya que estas variaciones son las que mayor impacto tienen en el precio de la acción y, por ende, en el valor de la firma. En este punto podemos relacionar la relevancia que toma la asimetría de información entre los administradores y el mercado, en línea con lo que plantearon Miller y Rock (1985), dado que la gerencia, a partir de información disponible que no tiene el mercado, busca dar una señal al mismo a favor de sus intereses.

Asimismo, Fisher se enfoca en ver cómo los inversionistas perciben el valor de una compañía dependiendo de su política de repartición de dividendos. En este sentido, aclara que la mayoría de los inversionistas que participan o buscan participar en acciones de compañías que no reparten dividendos esperan que el valor de mercado de estas sea inferior al de una entidad que reparte dividendos. En línea con lo anterior, la percepción del inversionista sobre la política de repartición de dividendos va de la mano con la política fiscal sobre estos, lo que hace que en lugares donde la tasa impositiva es alta los inversionistas prefieran participar en compañías con bajos niveles de repartición de dividendos.

Por último, Fisher concluye que los diferentes factores que afectan las decisiones de repartición de dividendos (impuestos, costos de transacción, liquidez de la firma tomada como la disponibilidad de recursos para pagar dividendos y las preferencias de los inversionistas) terminan llevando a que no se tenga claridad sobre cuáles son los principales determinantes que conducen a que una firma reparta o no dividendos, dada la inexistencia de relaciones entre las variables analizadas.

Es a partir de este punto donde se empieza a ver en la teoría financiera, cómo los académicos empiezan a buscar establecer relaciones entre los diferentes determinantes que motivan la política de repartición de dividendos, donde los impuestos son una de las principales variables por analizar.

Es entonces cuando, debido a la relevancia de los impuestos a la hora de determinar la política de dividendos, cobra mayor fuerza la necesidad de entender el efecto de la política impositiva dentro de la ecuación de los dividendos. En línea con lo anterior, el trabajo realizado por Bernheim (1990) toma sentido ya que busca explicar la relación entre las políticas de dividendos y los dividendos. Para esto, el autor elabora un modelo teórico que pretende establecer cómo las compañías buscan mejorar su percepción de rentabilidad en el mercado a través de la distribución de caja a sus accionistas. Para esto, Bernheim asume que para una entidad es indiferente realizar una recompra de acciones o pagar dividendos, 
sin embargo, en su modelo los dividendos mantienen una mayor tasa impositiva que aquella que se le cobra a la ganancia de capital de los inversionistas. El modelo elaborado por Bernheim se construye partiendo de una maximización de la rentabilidad de la firma, donde la administración tiene como objetivo enviar señales al mercado a través de pagos en cash al accionista/inversionista. Con este estudio el autor logró demostrar que, bajo ciertas condiciones favorables, las compañías pagarán dividendos independientemente de si las tasas impositivas al pago de estos recursos son superiores a las tasas impositivas de la ganancia de capital, contrario a lo que se venía aplicando a la fecha. Asimismo, Bernheim concluye que algunas compañías estarían dispuestas a emitir mayor nivel de patrimonio con el objeto de mantener una política estable de dividendos, a pesar de que esto genere mayores obligaciones fiscales.

Por su parte, las compañías que realizan recompra de acciones o pagan dividendos tienen una mejor percepción en el mercado frente a las que no lo hacen, por lo cual se ve un crecimiento en el valor de las firmas. Asimismo, el efecto marginal en el precio de la acción de una compañía que realiza recompra de acciones puede ser positivo o negativo dependiendo si la firma es de alta o baja calidad. En el caso de una compañía con menor calidad crediticia, este efecto será positivo, mientras que las compañías con mejor desempeño financiero se verán impactadas negativamente.

La investigación concluye afirmado que los impuestos a los dividendos son económicamente irrelevantes, a la hora de tomar las decisiones de políticas de pago de la firma, contrario a lo encontrado por otros autores investigados, donde las políticas fiscales afectaban las inversiones en la firma.

Si bien académicamente las investigaciones arrojaban que el comportamiento del pago de dividendos de la firma dependía de muchas variables, y que no necesariamente estos afectaban de igual manera a las compañías, todos los estudios que se habían realizado estaban enfocados en el mercado de Estados Unidos o en mercados desarrollados, por lo cual surgió el cuestionamiento de si estos resultados se replicarían en empresas que pertenecieran a un contexto macroeconómico diferente. Precisamente, para revisar si los determinantes del pago de dividendos de una firma en un país más favorable se mantenían en los países en desarrollo, Glen, Karmokolias, Miller y Shah (1995) llevaron a cabo una aproximación empírica al problema.

En este estudio, los autores compararon el comportamiento del pago de dividendos en los países desarrollados frente a los países emergentes. A lo largo de este estudio se exploró el comportamiento de pago de dividendos de diferentes 
entidades situadas en distintas zonas geográficas y que tienen entornos económicos diversos. Asimismo, el estudio logra determinar cómo las políticas de dividendos de las firmas que se encuentran en mercados emergentes no siguen las "normas tradicionales" 5 de la repartición de dividendos, e incluso, se observa una mayor volatilidad en dichas políticas comparado con el comportamiento de las políticas de repartición de dividendos observadas en países desarrollados.

Este estudio (Glen, Karmokolias, Miller y Shah, 1995) partió de un planteamiento teórico acompañado de un estudio empírico, tomando como punto de partida información disponible en los mercados que permitió establecer cuáles son las principales diferencias que se observan entre estas zonas socioeconómicas diferentes. Para elaborar esta investigación se utilizó información de 10 países (Chile, India, Jamaica, México, Filipinas, Tailandia, Turquía, Zimbabwe, Japón y Estados Unidos) para los periodos comprendidos entre 1987 y 1994. El estudio se enfocó en las siguientes variables y su relación entre sí:

a. El pago de dividendos entendido como la dividend Yield.

b. La ratio obtenida entre el precio y la ganancia por acción.

c. La evolución del precio de la acción frente al pago de dividendo.

d. Las diferencias entre las tasas de impuestas a los dividendos y la ganancia de capital.

Como conclusiones alcanzadas por este se tienen que:

a. Las estrategias para la elaboración de la política de dividendos de las empresas situadas en países emergentes difieren significativamente de las empresas localizadas en países desarrollados.

b. Dadas las mayores necesidades de reinversión de capital que tienen las firmas de los países emergentes, estos presentan menores tasas de reparto de dividendos que sus pares localizados en países desarrollados (hasta $2 / 3$ partes de lo evidenciado en las firmas de países desarrollados).

c. Las empresas que participan en los mercados emergentes, pese a mantener expectativas constantes sobre la repartición de dividendos, no se preocupan

5 Las normas tradicionales son definidas por los autores como los determinantes que establecen la política de dividendos. Por ejemplo, a mayor rentabilidad se tiene una mayor tasa de reparto de dividendos. 
tanto por la volatilidad de los pagos, contrario a lo observado en los mercados desarrollados.

d. La administración de las firmas que se encuentran en mercados emergentes es propensa a mantener una política de repartición con bajos o nulos dividendos, dado el potencial de crecimiento que ven estos en la firma y que demandaran mayor caja en la compañía.

e. Algunos gobiernos de países emergentes juegan un papel importante en la determinación de las políticas de dividendos de las firmas, ya que buscan incentivar la inversión extranjera a través de políticas de protección al inversionista como lo es una tasa de reparto mínima de dividendos.

Como se ha venido apreciando a lo largo de la presentación, la solución a la incógnita del por qué se reparten dividendos tenía respuestas muy amplias, donde las variables exógenas (localización geográfica, coyuntura macroeconómica, entre otras) mostraban cierta relación con el establecimiento de las políticas de repartición de dividendos. Es a partir de este punto donde se hicieron necesarias aproximaciones empíricas al problema para así establecer cuáles son los principales determinantes que llevan a que una firma page o no dividendos.

En el año 2010, Amarjit, Nahum y Tibrewala (2010) realizaron una aproximación empírica a la problemática buscando establecer cuáles son las determinantes que llevaban a las firmas de Estados Unidos a pagar dividendos. Para esto adelantaron un análisis de regresión multivariada sobre información de 500 empresas públicas pertenecientes a las industrias manufactureras y de servicios. Los autores escogieron un año de información (2007) para mantener un mismo contexto a lo largo de la muestra. Del total de los 500 datos de entrada tan solo 266 fueron utilizables, esta fue la muestra definitiva sobre la cual se corrió la regresión. En este estudio, los autores querían ver cómo la rentabilidad, el flujo de caja, los impuestos, el crecimiento de las ventas, la percepción del mercado, el apalancamiento y la industria afectaban el nivel de pago de dividendos (medido como Dividendos anuales/Utilidad neta).

Para los autores, la rentabilidad mantiene una relación positiva con la tasa de reparto de dividendos en la misma dirección que lo que da a pensar la intuición. En este sentido, se midió la rentabilidad como el EBITD/Total de activos, buscando ver cuánta rentabilidad operativa era generada por los activos de la compañía.

Por su parte, los autores sostienen que la capacidad de generación de flujo de caja influye de manera positiva en la tasa de reparto de dividendos de la firma, donde a mayores volúmenes de generación de caja mayor será el pago de 
dividendos. Para medir esta variable, se consideró al logaritmo natural del flujo de caja libre de la entidad.

En adición a lo anterior planteado, los autores buscan medir cómo los impuestos tienen un impacto en la capacidad de pago de la firma. En este sentido, se plantean que los impuestos impactan de manera negativa a la tasa de repartición de dividendos, alineado con lo planteado históricamente. En este sentido, en el estudio, los impuestos se midieron como la provisión de impuestos en el Estado de Resultados/Utilidad Neta antes de impuestos.

Para medir la percepción de mercado, los autores utilizaron Market-to-Book Value, medido como el precio de la acción a comienzo de año/activos netos por acción. Esta variable busca observar el comportamiento de la compañía frente al mercado, y así ver la influencia de este en los dividendos. De acuerdo con lo planteado por Amarjit, Nahum y Tibrewala (2010) existe una relación positiva entre ambos factores.

Dentro de los planteamientos realizados en el estudio se observa la manera como el apalancamiento afecta negativamente a la entidad. En línea con la percepción intuitiva, las empresas con mayores niveles de apalancamiento deberían tener una menor tasa de reparto de dividendos, para medir esta variable se utilizó la relación pasivo/patrimonio.

Con la relación del crecimiento en ventas y los dividendos, los autores buscaban mostrar cómo se afectaba positivamente la tasa de reparto de dividendos a media que el performance financiero mantiene una tendencia creciente. Esta variable fue medida como ventas añol/ventas año2 menos 1.

Finalmente, los autores crearon una variable dummy de instrucción donde asignaban un valor 0 a las industrias de servicios y un valor 1 para las industrias manufactureras. De acuerdo con lo planteado en su trabajo, se esperaba que las empresas tuvieran comportamientos similares entre sí.

Las principales conclusiones obtenidas arrojaron resultados diferentes para cada una de las industrias, lo que mostró que las empresas de servicios explican la repartición de dividendos de manera diferente a las empresas de la industria manufacturera. Asimismo, en la muestra realizada se observó la irrelevancia de ciertas relaciones positivas existentes, como que a mayor crecimiento en ventas se tiene un mayor pago de dividendos, esto mostró resultados contrarios a los históricamente evidenciados.

Otro de los estudios empíricos sobre el problema de los determinaste de la repartición de dividendos fue el expuesto por Vera (2007), donde el autor, a partir de un modelo econométrico, busca establecer cómo diferentes hipótesis planteadas 
sobre la política de dividendos aplican en el mercado español. En este estudio, Vera nos muestra cuáles son las hipótesis planteadas por los autores respecto a los determinantes de dividendos a lo largo de la historia y las compara con los resultados obtenidos por este.

Las hipótesis que el autor busca probar se presentan en la tabla 1.

Tabla 1: Determinantes de la repartición de dividendos en Vera (2007)

\begin{tabular}{|c|c|c|c|}
\hline $\begin{array}{c}\text { Variable } \\
\text { independiente }\end{array}$ & $\begin{array}{l}\text { Variable } \\
\text { dependiente }\end{array}$ & Trabajos anteriores & $\begin{array}{l}\text { Impacto sobre variable } \\
\text { dependiente }\end{array}$ \\
\hline \multirow{4}{*}{$\begin{array}{l}\text { Política de } \\
\text { dividendos }\end{array}$} & Riesgo & $\begin{array}{l}\text { Venkatesh (1989) } \\
\text { Chen y Steiner (1999) }\end{array}$ & Negativo \\
\hline & Endeudamiento & $\begin{array}{l}\text { Jensen, Solberg y Zorn (1992) } \\
\text { Chen y Steiner (1999) } \\
\text { Merik, Kyj, Merie y Lacke (2002) }\end{array}$ & Negativo \\
\hline & \multirow{2}{*}{ Propiedad } & Chen y Steiner (1999) & Negativo \\
\hline & & Merik, Kyj, Merie y Lacke (2002) & No significativo \\
\hline \multirow{8}{*}{ Riesgo } & $\begin{array}{l}\text { Política de } \\
\text { dividendos }\end{array}$ & $\begin{array}{l}\text { Chen y Steiner (1999) } \\
\text { Merik, Kyj, Merie y Lacke (2002) }\end{array}$ & Negativo \\
\hline & \multirow{4}{*}{ Endeudamiento } & $\begin{array}{l}\text { Baxter (1967) } \\
\text { Long y Malitz (1985) } \\
\text { Friend y Lang (1988) } \\
\text { Crutchley y Hansen (1989) } \\
\text { Bathala, Moon y Rao (1994) } \\
\text { Chen y Steiner (1999) } \\
\text { Merik, Kyj, Merie y Lacke (2002) }\end{array}$ & Negativo \\
\hline & & Kin y Sorenson & Positivo \\
\hline & & $\begin{array}{l}\text { Ferri y Jones (1979) } \\
\text { Flath y Knoeber (1980) } \\
\text { Kester (1986) }\end{array}$ & No significativo \\
\hline & & Jensen, Solberg y Zorn (1992) & Negativo/ No significativo \\
\hline & \multirow{3}{*}{ Propiedad } & Jensen, Solberg y Zorn (1992) & No significativo \\
\hline & & Chen y Steiner (1999) & No lineal \\
\hline & & Merik, Kyj, Merie y Lacke (2002) & Negativo \\
\hline
\end{tabular}




\begin{tabular}{|c|c|c|c|}
\hline $\begin{array}{c}\text { Variable } \\
\text { independiente }\end{array}$ & $\begin{array}{l}\text { Variable } \\
\text { dependiente }\end{array}$ & Trabajos anteriores & $\begin{array}{l}\text { Impacto sobre variable } \\
\text { dependiente }\end{array}$ \\
\hline \multirow{6}{*}{$\begin{array}{l}\text { Endeuda- } \\
\text { miento }\end{array}$} & \multirow{2}{*}{$\begin{array}{l}\text { Política de } \\
\text { dividendos }\end{array}$} & $\begin{array}{l}\text { Chen y Steiner (1999) } \\
\text { Merik, Kyj, Merie y Lacke (2002) }\end{array}$ & Negativo \\
\hline & & Jensen, Solberg y Zorn (1992) & Negativo/ No significativo \\
\hline & \multirow[b]{2}{*}{ Riesgo } & Chen y Steiner (1999) & No nignificativo \\
\hline & & Adams, Almeida y Ferreira (2005) & $\begin{array}{l}\text { Positivo, Negativo o no } \\
\text { significativo }\end{array}$ \\
\hline & \multirow{2}{*}{ Propiedad } & $\begin{array}{l}\text { Jensen, Solberg y Zorn (1992) } \\
\text { Merik, Kyj, Merie y Lacke (2002) }\end{array}$ & No significativo \\
\hline & & Chen y Steiner (1999) & Negativo \\
\hline \multirow{6}{*}{ Propiedad } & $\begin{array}{l}\text { Política de } \\
\text { dividendos }\end{array}$ & $\begin{array}{l}\text { Rozeff (1982) } \\
\text { Chen y Steiner (1999) } \\
\text { Meric, Kyj, Meric y Lake (2002) }\end{array}$ & Negativo \\
\hline & \multirow{3}{*}{ Riesgo } & $\begin{array}{l}\text { Saunders, Strock y Travlos (1990) y } \\
\text { Steiner (1999) }\end{array}$ & Positivo \\
\hline & & $\begin{array}{l}\text { Ameihud y Lev (1981) } \\
\text { May (1995) } \\
\text { Chen, Steiner y Whyte (2005) }\end{array}$ & Negativo \\
\hline & & Adams, Almeida y Ferreira (2005) & $\begin{array}{l}\text { No significativo y } \\
\text { significativo }\end{array}$ \\
\hline & \multirow[b]{2}{*}{ Endeudamiento } & Kim y Sorenson (1986) & Positivo \\
\hline & & $\begin{array}{l}\text { Friend y Hasbrouck (1987) } \\
\text { Friend y Lang (1988) } \\
\text { Chen y Steiner (1999) } \\
\text { Merik, Kyj, Merie y Lacke (2002) }\end{array}$ & Negativo (Vera, 2007) \\
\hline
\end{tabular}

Fuente: Vera (2007).

Para realizar la comprobación empírica de estas teorías, Vera trabajó con una muestra de 65 empresas no pertenecientes al sector financiero que cotizaban en la Bolsa de Valores entre 1995 y el año 2000, y obtuvo 390 datos anuales. Con la información obtenida se realizaron cuatro regresiones econométricas buscando establecer cómo se relacionaban entre sí el pago de dividendos, el endeudamiento, el riesgo y la propiedad de los insiders.

Las principales conclusiones encontradas por Vera en su estudio fueron: 
a. A mayor sea el costo de emisión de nuevas acciones para la firma se desincentiva el pago de dividendos de la firma. En línea con lo planteado por Jensen, Solberg y Zorn (1992).

b. Hay una influencia positiva de la propiedad con el pago de dividendos. Este resultado, según el autor, puede derivar de la preferencia de los gestores en el pago de dividendos en detrimento de las ganancias de capital, difiriendo de los resultados obtenidos por Chen y Steiner (1999) en el mercado norteamericano.

c. El nivel de endeudamiento restringe el pago de dividendos. A mayor sea el endeudamiento de una entidad más restringido será su flujo de caja y capacidad de incrementar su deuda por lo que tiende a repartir menores niveles de dividendos para autofinanciarse.

d. El riesgo es menor en compañías que presentan mayores pagos de dividendos. Esto se interpreta como una señal positiva del mercado.

e. Las empresas con mayor volatilidad pagan menores tasas de dividendos, dado que existe una relación negativa entre el riesgo y el pago de dividendos.

Si bien los trabajos empíricos mostraban una aproximación al resultado del problema, estos se habían realizado en mercados bursátiles, con buena penetración de mercado, mas no en mercados emergentes donde hay mayor limitación de información. Dado esto, no se podría establecer lo planteado por Glen, Karmokolias, Miller y Shah (1995), donde la situación coyuntural influía de manera significativa en los determinantes de la política de dividendos.

En línea con la anterior problemática aparecen trabajos como el presentado por Mehta (2012), en que se realizó un estudio en empresas pertenecientes a la Bolsa de Emiratos Árabes y se buscó, a través de una regresión multivariada, determinar qué tenían en común las empresas que pagaban dividendos y cuáles podrían ser las características de la firma que resultaran en ciertos niveles de tasa de reparto de dividendos.

Para este trabajo, Mehta utilizó información financiera de 44 entidades corporativas/empresariales entre los periodos de 2005-2009, las cuales estaban listadas en la Bolsa de Valores de Abu Dhabi. Se destaca que las instituciones financieras fueron removidas del estudio, dado su carácter regulado, y que estas se comportan de manera diferente a las empresas corporativas.

Este estudio quería demostrar si las empresas que mantenían políticas de reparto de dividendos tenían características comunes entre ellas. Para esto, el autor buscó saber cómo ciertas variables -que se nombrarán a continuación- repercutían 
en la ratio de pago de dividendos (dividendos pagados en efectivo/ Utilidad Neta*100). A continuación, presentamos las variables independientes del Modelo realizado en este trabajo:

a. La primera variable independiente que se planteó Mehta es la rentabilidad, partiendo del precepto de que las empresas con mayores niveles de rentabilidad deberían generar un mayor retorno a sus inversionistas y, por ende, un aumento en la utilidad de una firma derivaría en un aumento en la tasa de reparto de dividendos. Para medir esta variable, el autor utilizó la rentabilidad sobre capital invertido (ROE) y la rentabilidad sobre activos (ROA) como medidas de rentabilidad.

b. La segunda variable independiente del modelo fue la percepción de riesgo del inversionista. De acuerdo con lo planteado por el autor, entre mayor sea la percepción de riesgo que se tenga sobre un activo este deberá tener un mayor retorno, por ende, se esperaría que las empresas que mantienen mayores niveles de riesgo generen mayores niveles de retorno a los inversionistas. Para medir esta variable, Mehta utilizó la ratio de "precio de la acción/la ganancia por acción", la cual, de manera implícita, refleja la percepción de riesgo del mercado en el activo (mayores tasas de retorno por acción representan mayores riesgos por remunerar).

c. La tercera variable del modelo fue el apalancamiento. De acuerdo con lo esperado por la intuición, las empresas con mayores niveles de endeudamiento tendrán menos recursos disponibles y, por consiguiente, mantendrán menores tasas de reparto de dividendos. Para medir esta variable, Mehta utilizó el apalancamiento (pasivo/patrimonio).

d. La cuarta variable independiente fue el tamaño de la firma. Se espera que las empresas que tiene un mayor tamaño mantengan mayores niveles de remuneración a sus accionistas, por ende, debe existir una relación positiva entre esta variable y la tasa de reparto de dividendos de una entidad. Esta variable fue medida como el logaritmo natural de los activos.

e. Finalmente, la última variable independiente utilizada en el estudio fue el nivel de liquidez de la firma. En línea con lo expuesto en el estudio, la capacidad de repartir dividendos de la firma está relacionada con la capacidad de tener recursos de liquidez para realizar el pago, es decir, que a mayores niveles de liquidez las entidades deberían tender a repartir mayor cantidad de dividendos. Para medir la liquidez, el autor utilizó la razón corriente (activo corriente/ pasivo corriente). 
Dentro de las principales conclusiones de Metha en esta investigación, se observa que el tamaño de la firma, la rentabilidad y la percepción de riesgo explican el $42 \%$ de la política de dividendos. Contrario a lo esperado por la intuición, el apalancamiento y la liquidez no son significativos para explicar el pago de dividendos, con lo cual se puede inferir que las empresas buscan realizar el pago de estos sin importar las afectaciones que esto tenga en su estructura de capital o posición de liquidez.

Otra de las investigaciones realizadas fue la llevada a cabo por Azouzi y Jarboui (2012), por medio de la cual tratan de explicar el comportamiento de la política de repartición de dividendos basándose en la conducta de la alta gerencia (CEO). En este estudio, los autores investigan el comportamiento de $100 \mathrm{CEO}$ de empresas localizadas en Túnez y, con base en un cuestionario elaborado por ellos, desarrollan una Red bayesiana tratando de determinar cuál es la influencia que tiene el comportamiento de los CEO a la hora de determinar la ratio de pago de dividendos de una firma. Dentro de las definiciones realizadas por los autores, se decide ver el comportamiento del CEO frente a: i) aversión al riesgo, ii) la sobreconfianza y iii) el optimismo que estos mantienen.

Para la construcción del modelo realizaron cuatro pasos: i) identificación de la compañía (tamaño, industria, accionistas, etc.); ii) determinación del nivel de aversión a las pérdidas; iii) determinación del nivel de optimismo del CEO; iv) nivel de sobreconfianza del CEO (explicados en el Marco Teórico). Una vez hecho esto, construyeron la Red bayesiana y se corrieron los resultados obteniendo como conclusiones:

a. Al contrario de lo que se había planteado académicamente, los líderes con mayores niveles de optimismo o con sobreconfianza acerca del futuro de la firma tienden a subestimar la oportunidad de bancarrota de la compañía, razón por la que incrementan sus ratios de apalancamiento, impulsando al CEO a mantener una política generosa de reparto de dividendos.

b. El optimismo del CEO está relacionado positivamente con la repartición de dividendos. Estos CEO tienden a subestimar el retorno del mercado en el futuro y a repartir mayores niveles de dividendos. Entre mayor sea el nivel de optimismo de la administración frente al futuro de la firma mayores serán las ratios de dividendos. 
c. Existe una relación directa y positiva entre la aversión a las pérdidas y las políticas de dividendos. Un líder adverso a las pérdidas escogerá una política de dividendos más generosa que los anteriores.

d. Finalmente, el comportamiento de los CEO está alineado con la teoría financiera, donde la administración ajustará su política de dividendos basada en la capacidad de evaluar nuevas alternativas y percepción del riesgo, buscando maximizar el valor de la compañía.

Para ver el comportamiento de países en desarrollo se analizó el caso de Nigeria, donde los autores Uwigbe, Jafaru y Anijesushola (2012) buscaron encontrar la relación que tiene el desempeño financiero de una compañía con la política de dividendos de esta. Para ello, los autores realizaron una investigación sobre la información financiera de 50 empresas nigerianas inscritas en la Bolsa de Nigeria, para los periodos comprendidos entre 2006 y 2010. Para hacer el análisis de datos los autores crearon un modelo de regresión multivariado buscando encontrar las relaciones existentes entre el pago de dividendos con el tamaño de la firma, la rentabilidad y la estructura del accionariado.

Para esto, los autores definieron como variables independientes:

a. Tamaño de la empresa: total número de miembros de directores dentro de la junta directiva.

b. Estructura del accionariado: medida como el porcentaje de las acciones en cabeza de los directores de la entidad (administración).

c. Rentabilidad: medida como el Return on Equity (ROE).

La variable independiente fue la ratio de pago de dividendos medida como dividendo por acción sobre utilidad por acción.

Dentro de las principales conclusiones obtenidas por los autores se encontró que el modelo predice el $74 \%$ del comportamiento del pago de dividendos de las firmas nigerianas, respondiendo de manera positiva a la hipótesis planteada por los autores donde efectivamente el pago de dividendos se ve afectado de manera significativa por el desempeño que tienen las entidades financieras.

De la misma manera, concluyen positivamente que las empresas con mayores tamaños tienden a pagar mayores niveles de dividendos debido a que tienen más acceso a los mercados de deuda/capitales que les permite conseguir recursos para mantener un dividendo constante. 
Por otra parte, las empresas nigerianas tienden a disminuir el riesgo político de su junta directiva a través de una política estable de dividendos en el tiempo.

Finalmente, las entidades prefieren tener un mayor pago de dividendos si esto les permite reducir sus costos de agencia dado que estos tienden a incrementarse a medida que hay una dispersión del accionariado.

Otra aproximación a los determinantes de la política de dividendos fue la realizada por Cristea y Cristea (2017), donde los autores buscaron entender cuáles eran los principales determinantes de la política de dividendos en la economía de Rumania. Para determinar los factores realizaron una regresión lineal multivariada para poder establecer aquellos en común en las empresas que pagaban dividendos en la Bolsa de Bucarest.

La data que utilizaron Cristea y Cristea (2017) en la investigación corresponde a información financiera de empresas y listadas en la Bolsa de Bucarest, que se compone de 701 observaciones disponibles para el análisis. Las variables independientes escogidas por los autores se basaron en las que otros investigadores utilizaban normalmente en estos ejercicios, ellas son:

- Tamaño de la empresa: esta variable fue definida como: i) el logaritmo natural de los activos de la entidad, y ii) el valor en libros del dividendo de deuda sobre total activos.

- Apalancamiento: definido como pasivo sobre patrimonio.

- Crecimiento: medido como el crecimiento anual de las ventas.

- Rentabilidad: medida como utilidad neta sobre el patrimonio de los accionistas.

- Liquidez: medida como indicador de prueba ácida.

- Crecimiento económico: medido como el crecimiento de Rumania.

En este caso, al igual que los otros estudios analizados, la variable dependiente fue el nivel de tasa de reparto de dividendos, la cual se midió con el dividendo por acción sobre el precio de la acción.

El modelo obtenido por los autores arrojó un nivel de predictibilidad elevado (79\%), en donde todas las variables son significativas para el pago de dividendos.

El primer hallazgo de la investigación es la relación positiva entre la rentabilidad de la entidad y el pago de dividendos, donde las empresas con mayores niveles de retorno tienden a pagar mayores niveles de dividendos que las menos rentables. 
Asimismo, existe una relación negativa entre el tamaño y el pago de dividendo, donde las empresas más pequeñas presentan mayores niveles de dividendos, en contra de lo que teóricamente se había planteado por otros autores.

En línea con lo que la academia indica, se observó una relación negativa entre el apalancamiento y la tasa de pago de dividendos, donde empresas con mayores niveles de apalancamiento tienden a repartir menores niveles de dividendos.

Finalmente, la investigación validó la relación positiva existente entre la liquidez y el reparto de dividendos, en donde empresas con mayores niveles de liquidez repartían mayores niveles de inventario.

Si bien estos estudios empezaron a esbozar una realidad sobre los determinaste de la política de dividendos en diferentes zonas geográficas, no se observaba que los estudios fueran concluyentes para empresas localizadas en zonas de desarrollo macroeconómico diferente. Dado lo anterior, y la falta de estudios realizados sobre este tema en las economías de Latinoamérica, en este estudio se pretende llevar a cabo una aproximación empírica para determinar cuáles son las principales variables que llevan a que una firma latinoamericana reparta dividendos.

\section{Metodología y base de datos}

Dentro de esta investigación se buscó, a través de una regresión multivariada, ver cuáles son los determinantes que explican de mejor manera la política de pago de dividendos de las empresas latinoamericanas.

Se escogió utilizar este tipo de análisis de datos buscando poder comparar si los hallazgos de Mehta (2012) y Amarjit, Nahum y Tibrewala (2010) sobre los determinantes de la política de dividendos para las empresas de Emiratos Árabes y Estados Unidos, se mantienen o difieren de los determinantes de la política de dividendos de las empresas en Latinoamérica.

Para la construcción de la regresión lineal múltiple se partió de los trabajos realizados por Amarjit, Nahum y Tibrewala (2010) y Mehta (2012) a la hora de definir las variables por utilizar dentro de la regresión.

En este sentido, la regresión lineal múltiple se definió de la siguiente manera:

Pago de Dividendos $=\beta 0+\beta 1 * \operatorname{tamaño}+\beta 2 *$ rentabilidad $+\beta 3 *$

Riesgo+ $\beta 4 *$ Impuestos $+\beta 5^{*}$ Apalancamiento $+\beta 6 *$ Liquidez

Donde $\beta 0, \beta 1, \beta 2, \beta 3 \ldots \beta 6$ son los coeficientes de regresión de las variables independientes que se presentan a continuación: 
- Tamaño de la empresa. En línea con las investigaciones analizadas, se plantea que existe una relación positiva entre el tamaño de la firma y la tasa de repartición de dividendos que esta mantiene.

Hipótesis: entre mayor sea el tamaño la firma, la ratio de pago de dividendos aumentará, por ende, existe una relación positiva entre esta variable y la variable dependiente.

En este ejercicio, el tamaño de la firma será medido como:

Tamaño = Logaritmo natural de los activos de la firma en USD

- Rentabilidad. En la teoría se plantea la relación directa entre la rentabilidad de la compañía y la capacidad de pago de dividendos de la firma. De acuerdo con lo planteado por Litner (1956) y Baker (1985) el patrón de comportamiento de pago de dividendos de una firma está influenciado principalmente por los niveles de dividendos pagados durante el año anterior y la utilidad conseguida durante el año en vigencia. Asimismo, en el trabajo realizado por Mehta (2012) encontramos que las empresas con indicadores de rentabilidad estables y de mayor tamaño son más propensas a mantener mayores niveles de generación de caja y, por ende, lograr mantener una mayor tasa de reparto de dividendos. Hipótesis: la rentabilidad afecta positivamente al pago de dividendos, entre mayor sea la rentabilidad de la compañía mayor será el pago de dividenos. Para la medición de la rentabilidad de la entidad se utilizarán tres ratios:

$$
\begin{gathered}
\text { Rentabilidad }=\text { EBIT } /(\text { Total Activos }) \\
\text { ROA }=(\text { Utilidad Neta }) /(\text { Total Activos }) \\
\text { ROE }=(\text { Utilidad Neta }) /(\text { Total Patrimonio })
\end{gathered}
$$

La escogencia de estos tres indicadores para medir la rentabilidad se explica por:

a. Ebit/Total Activos: con este indicador se busca ver si la política de dividendos está relacionada directamente con la rentabilidad operativa de las empresas.

b. Con el ROA buscamos establecer si la rentabilidad total de los activos presenta una relación directa con el dividendo. Este indicador se diferencia del anterior, ya que partimos de la generación de utilidad neta (utilidad sobre la cual se distribuyen dividendos); en este sentido, buscamos establecer si 
la generación de rentabilidad neta de todos los activos muestra la relación directa con la política de distribución de dividendos de las firmas.

c. Finalmente, con el ROE buscamos ver la relación entre la rentabilidad del accionista y la remuneración que este recibe a través de los dividendos.

Adicionalmente a estas explicaciones, este trabajo busca comparar los resultados con los obtenidos en los diferentes estudios que sirvieron de base para el desarrollo de este modelo (Mehta, 2012; Amarjit, Nahum y Tibrewala, 2010; Uwigbe, Jafaru y Anijesushola, 2012; Cristea y Cristea, 2017), por lo cual se utilizaron las mismas variables que ellos usaron para medir la rentabilidad de las firmas.

- Riesgo. El planteamiento teórico muestra que los inversionistas esperan un mayor pago de dividendos en las compañías que representan una posición más riesgosa. De acuerdo con el estudio de Mehta (2012), dada la relación lineal entre riesgo-retorno (a mayor riesgo mayor retorno), el riesgo de una firma puede medirse a través del comportamiento existente entre el precio y la ganancia (P/E ratio) dado que este indicador refleja la percepción de riesgo de la firma. En este orden de ideas, entre mayor sea la P/E (menor riesgo) mayor será el pago de dividendos de la entidad.

El indicador $\mathrm{P} / \mathrm{E}$ implícitamente incorpora la percepción del riesgo dados los ingresos futuros de una entidad. Un nivel alto de P/E sugiere que los inversionistas están esperando mayores niveles de crecimiento de ganancias en el futuro, comparado con las empresas que tienen un menor P/E (Fama y Fecnch, 1998; Puckett, 1964). Recaudar dividendos reduce el riesgo que tienen los accionistas en su flujo de caja, lo que implica un incremento del precio de la acción y del indicador P/E. (Mehta, 2012, p. 6)

Hipótesis: existe una relación positiva entre la percepción de riesgo de la empresa y su ratio de pago de dividendos.

El riesgo se mide como:

$$
\text { Riesgo }=(\text { Precio de la acción }) /(\text { ganancia por acción })
$$

- Impuestos. De acuerdo con el estudio realizado por Amarjit, Nahum y Tibrewala (2010), se establece que existe una relación positiva entre los impuestos y las tasas de distribución de dividendos. En este sentido, entre mayor sea la tasa impositiva sobre la repartición de dividendos frente a los impuestos a las ganancias de capital se tendrá una política más restrictiva de dividendos. 
Hipótesis: existe una relación negativa entre la tasa de impuestos a los dividendos y el indicador de pago de dividendos de la firma.

Esta variable será medida como:

Impuestos $=$ Tasa de Impuestos a los dividendos

- Apalancamiento. De acuerdo con las prácticas empíricas, la relación entre la estructura de capital de una compañía y los niveles de pago de dividendos. A mayor nivel de apalancamiento se ve un menor pago de dividendos, sin embargo, esto puede ser producto de las restricciones impuestas por sus acreedores a través de los covenants de limitación. Asimismo, se ve que las empresas con mayores niveles de apalancamiento tienden a reducir el nivel de dividendos pagados, buscando reducir los costos asociados al financiamiento externo (Mehta, 2012). Por otra parte, vemos que las entidades con altas tasas de crecimiento y pago de dividendos utilizan mayores niveles de deuda para financiar estos pagos (Amarjit, Nahum y Tibrewala, 2010).

Hipótesis: hay una relación negativa entre el apalancamiento (nivel de endeudamiento de la entidad) y la tasa de repartos de dividendos.

Este indicador será medido a través de dos variables:

Apalancamiento $=$ Pasivo $/$ Patrimonio

Deuda a Ebitda* $=($ Deuda Financiera $) /$ Ebitda

- Liquidez. La liquidez o posición de caja es una variable directamente relacionada con las tasas de pago de dividendos de una firma. Entre mayor sea la posición de caja de una entidad más probable es que dedique sus recursos al pago de dividendos. Resaltamos que entre peor sea la posición de liquidez de la entidad menor será la capacidad de generar pagos de dividendos en efectivo por parte de la entidad.

Hipótesis: existe una relación positiva entre el nivel de liquidez de la compañía y la ratio de dividendos de la firma. Esta variable se medirá como:

$$
\text { Liquidez }=(\text { Activo Corriente }) /(\text { Pasivo Corriente })
$$

* Nota: Ebitda (Earnings Before Interest, Taxes, Depreciation, and Amortization), es decir, beneficio bruto de explotación calculado antes de la deducibilidad. 
si bien se entiende que la razón corriente no es el mejor indicador para medir la liquidez real de una entidad, dado que el valor del activo corriente es un valor en libros y no uno de mercado. ${ }^{6}$ Dado que en este trabajo se buscó comparar los estudio realizados anteriormente por Mehta (2012); Amarjit, Nahum y Tibrewala (2010); Uwigbe, Jafaru y Anijesushola (2012); Cristea y Cristea (2017), se decidió mantener la variable de razón corriente dado que fue la más común utilizada para medir el indicador de liquidez en dichos estudios.

- País. Se creó una variable dummy para clasificar en la base de datos el país al que pertenece cada una de las compañías. En este orden de ideas, se asignó un número del 1 al 6 a cada uno de los países a los que pertenecen las compañías analizadas, tal como se muestra tabla 2.

Tabla 2: Variable dummy para el país

\begin{tabular}{|c|c|}
\hline \multicolumn{2}{|c|}{ País } \\
\hline Brasil & 1 \\
\hline Colombia & 2 \\
\hline Chile & 3 \\
\hline México & 4 \\
\hline Panamá & 5 \\
\hline Perú & 6 \\
\hline
\end{tabular}

- Industria. Al igual que con los países, se incluyó una variable dummy para determinar la relevancia de la industria dentro de la determinación de la política de pago de dividendos; para esto se asignó un valor de 1 a 11 a cada una de las industrias tal como se muestra en la tabla 3.

6 Cuando una empresa tenga que liquidar sus activos corrientes, esta no podrá venderlos al mismo valor al que los registra en libros (por ejemplo, una operación de factoring descuenta el valor de las cuentas por cobrar). Por su parte, los pasivos sí se encuentran a un valor de mercado, es decir, la entidad tiene obligaciones con terceros cuyo valor ya fue establecido por un servicio prestado y que la empresa mantendrá a lo largo del tiempo. Teniendo en cuenta lo anterior, el indicador de razón corriente puede no ser la mejor medida de la liquidez de una firma. 
Tabla 3: Variable dummy para la industria

\begin{tabular}{|c|c|}
\hline \multicolumn{2}{|c|}{ Industrias } \\
\hline Aerolíneas & 1 \\
\hline Alimentos y Bebidas & 2 \\
\hline Cemento & 3 \\
\hline Construcción & 4 \\
\hline Energía & 5 \\
\hline Industrial & 6 \\
\hline Minas & 7 \\
\hline Oil \& Gas & 8 \\
\hline Petroquímico & 9 \\
\hline Retail & 10 \\
\hline Telecomunicaciones & 11 \\
\hline
\end{tabular}

Finalmente, la variable dependiente de este modelo será la tasa de reparto de dividendos, la cual se define como:

Tasa de reparto de Dividendos $=($ Dividendos pagados en efectivo $) /$ (Utilidad Neta)

Una vez definida la variable del modelo se construyó la base de datos por medio de la cual se trabajaría, la cual fue construida utilizando información existente en la base de datos de Bloomberg, e información pública disponible en las páginas web de cada una de las entidades analizadas.

La base de datos construida cuenta con información financiera de 97 empresas latinoamericanas pertenecientes a 6 países y 11 industrias diferentes, para los periodos anuales comprendidos entre diciembre de 2012 y diciembre 2018, lo que equivale a una base de datos con 679 datos de salida.

Dada la limitación de información disponible, las industrias que se observan derivan de la información disponible de las empresas, es decir, no existió un criterio específico para la selección de las industrias ya que lo que se hizo fue clasificar las empresas con información disponible según su tipo de industria, por lo cual la selección de esta fue el resultado de un proceso aleatorio (industria a la que pertenecía la entidad) y no a un criterio específico de selección. 
Finalmente, la inclusión de Panamá dentro de la muestra (una única empresa) corresponde a la compañía Copa Holdings, entidad que es referente de la industria de aviación en el continente y la cual fue agregada a propósito dentro de la base de datos, teniendo en cuenta la relevancia de la compañía en la industria a la que pertenece (aerolínea más rentable de América Latina).

Resaltamos que, dada la información limitada existente sobre todas las empresas seleccionadas, se debió limitar el periodo de análisis a solo 7 años de datos.

A continuación, en las tablas 4 y 5 resumimos la base de datos por industrias y por países analizados.

Tabla 4: Tabla base de datos por número de empresas

\begin{tabular}{|l|c|c|c|c|c|c|c|}
\hline \multicolumn{1}{|c|}{ Industria } & Brasil & Colombia & Chile & México & Panamá & Perú & Total \\
\hline Aerolíneas & 2 & 1 & 1 & 2 & 1 & - & 7 \\
\hline Alimentos & 3 & 2 & 1 & 7 & - & 2 & 15 \\
\hline Cemento & - & 1 & - & 1 & - & 1 & 3 \\
\hline Construcción & 2 & 3 & 3 & - & - & - & 8 \\
\hline Energía & 6 & 6 & 2 & 1 & - & - & 15 \\
\hline Industrial & 4 & 5 & 3 & 6 & - & - & 18 \\
\hline Minas & 1 & 1 & 1 & 1 & - & - & 4 \\
\hline Oil \& Gas & 1 & 5 & 2 & 1 & - & 1 & 10 \\
\hline Petroquímico & - & - & - & 2 & - & - & 2 \\
\hline Retail & 2 & 1 & 5 & 3 & - & 2 & 13 \\
\hline Telecomunicaciones & - & - & 1 & 1 & - & - & 2 \\
\hline Total & 21 & 25 & 19 & 25 & 1 & 6 & 97 \\
\hline
\end{tabular}

Fuente: elaboración propia.

Tabla 5: Tabla base de datos por datos de entrada

\begin{tabular}{|l|c|c|c|c|c|c|c|}
\hline \multicolumn{1}{|c|}{ Industria } & Brasil & Colombia & Chile & México & Panamá & Perú & Total \\
\hline Aerolíneas & 14 & 7 & 7 & 14 & 7 & - & 49 \\
\hline Alimentos & 21 & 14 & 7 & 49 & - & 14 & 105 \\
\hline Cemento & - & 7 & - & 7 & - & 7 & 21 \\
\hline Construcción & 14 & 21 & 21 & - & - & - & 56 \\
\hline
\end{tabular}




\begin{tabular}{|l|c|c|c|c|c|c|c|}
\hline \multicolumn{1}{|c|}{ Industria } & Brasil & Colombia & Chile & México & Panamá & Perú & Total \\
\hline Energía & 42 & 42 & 14 & 7 & - & - & 105 \\
\hline Industrial & 28 & 35 & 21 & 42 & - & - & 126 \\
\hline Minas & 7 & 7 & 7 & 7 & - & - & 28 \\
\hline Oil \& Gas & 7 & 35 & 14 & 7 & - & 7 & 70 \\
\hline Petroquímico & - & - & - & 14 & - & - & 14 \\
\hline Retail & 14 & 7 & 35 & 21 & - & 14 & 91 \\
\hline Telecomunicaciones & - & - & 7 & 7 & - & - & 14 \\
\hline Total & 147 & 175 & 133 & 175 & 7 & 42 & 679 \\
\hline
\end{tabular}

Fuente: elaboración propia.

Teniendo en cuenta la información segmentada que se presenta en las tablas 4 y 5 , se decidió realizar para la investigación tres análisis segmentados de la muestra:

1. Análisis sobre la base de datos completa.

2. Análisis de la data segmentado por industria.

3. Análisis de la base de datos dividido por países.

El objetivo de realizar esta subdivisión en el estudio fue analizar cómo varían los determinantes de la política de dividendos dependiendo de la región o industria de cada entidad. En este sentido, se puede ver el efecto que tiene una industria sobre el pago de dividendos, en línea con lo planteado por Amarjit, Nahum y Tibrewala (2010) y cómo la coyuntura de los países afecta la tasa de reparto de dividendos, en línea a lo visto por Glen, Karmokolias, Miller y Shah (1995).

Se resalta que la información financiera de la empresa panameña (única empresa de dicho país) fue incluida por tratarse de una de las entidades más relevantes de la industria aeronáutica latinoamericana. No se realizaron análisis estadísticos sobre las empresas panameñas teniendo en cuenta la información limitada que tiene la base de datos sobre dicho país.

Finalmente, una vez construida y clasificada la muestra se hizo un análisis de colinealidad entre las variables. De este resultado se observó la existencia de colinealidad en las variables de ROA y ROE, por lo cual se pasó a realizar un análisis de correlaciones parciales existentes entre las variables, la cual arrojó el resultado que se presenta en la tabla 6 . 


\begin{tabular}{|c|c|c|c|c|c|c|c|c|c|}
\hline 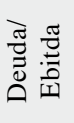 & 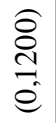 & $\begin{array}{l}0 \\
\hat{0} \\
0 \\
e \\
e\end{array}$ & $\begin{array}{l}\stackrel{\infty}{=} \\
=\end{array}$ & $\begin{array}{l}\overline{0} \\
\stackrel{0}{0} \\
0\end{array}$ & $\begin{array}{l}\frac{\hat{\infty}}{\tilde{\sigma}} \\
\stackrel{0}{e}\end{array}$ & 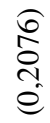 & $\frac{\widehat{Q}}{\stackrel{\mathbb{N}}{e}}$ & $\begin{array}{l}\text { సे } \\
\text { ठ } \\
\text { ठ }\end{array}$ & $\begin{array}{l}8 \\
\& \\
\&\end{array}$ \\
\hline $\begin{array}{l}\text { 띵 } \\
\text { 1) }\end{array}$ & 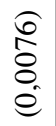 & 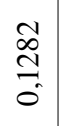 & $\begin{array}{l}\tilde{\infty} \\
\stackrel{\infty}{0}\end{array}$ & $\begin{array}{l}\widehat{ఠ} \\
\text { } \\
0 \\
\stackrel{e}{e}\end{array}$ & 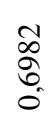 & $\begin{array}{l}\equiv \\
\overline{0} \\
0\end{array}$ & $\begin{array}{l}8 \\
\text { + } \\
\text { o. } \\
0\end{array}$ & \begin{tabular}{l}
8 \\
8 \\
8 \\
\hdashline
\end{tabular} & $\begin{array}{l}\text { ते } \\
\text { ठิ } \\
\text { o. }\end{array}$ \\
\hline 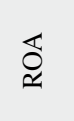 & $\begin{array}{l}\stackrel{\Omega}{\widehat{~}} \\
\text { O. } \\
0\end{array}$ & $\begin{array}{l}\hat{f} \\
\infty \\
\stackrel{0}{e} \\
\stackrel{e}{e}\end{array}$ & $\begin{array}{l}\widehat{\hat{d}} \\
\text { dे } \\
\text { é }\end{array}$ & 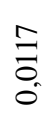 & 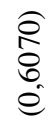 & $\begin{array}{l}\underset{\mathbb{S}}{0} \\
\stackrel{0}{e}\end{array}$ & $\begin{array}{l}8 \\
8 \\
8 \\
8\end{array}$ & \begin{tabular}{l}
8 \\
\multirow{+}{*}{} \\
$\infty$ \\
0
\end{tabular} & 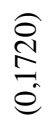 \\
\hline 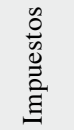 & $\begin{array}{l}\hat{\sigma} \\
\text { ఠิ } \\
\text { o }\end{array}$ & $\frac{\widehat{f}}{\stackrel{\Xi}{e}}$ & $\begin{array}{l}\underset{S}{\Delta} \\
0 \\
0\end{array}$ & 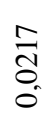 & $\begin{array}{l}\stackrel{0}{\stackrel{\infty}{a}} \\
\stackrel{0}{e}\end{array}$ & $\begin{array}{l}8 \\
8 \\
8 \\
8\end{array}$ & $\begin{array}{l}\widehat{\mathbb{S}} \\
\stackrel{\Xi}{0} \\
\stackrel{e}{e}\end{array}$ & $\begin{array}{l}\Xi \\
\bar{\sigma} \\
0\end{array}$ & $\begin{array}{l}\hat{2} \\
\stackrel{2}{0} \\
\hat{e}\end{array}$ \\
\hline 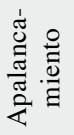 & $\begin{array}{l}\stackrel{\infty}{0} \\
\stackrel{N}{0} \\
\stackrel{0}{e}\end{array}$ & $\begin{array}{l}\stackrel{+}{O} \\
\text { Oे } \\
\text { O. }\end{array}$ & $\begin{array}{l}\hat{\overparen{े}} \\
\text { ते } \\
\hat{e}\end{array}$ & 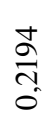 & $\begin{array}{l}8 \\
8 \\
8\end{array}$ & $\frac{\stackrel{\infty}{\hat{d}}}{\stackrel{e}{e}}$ & $\begin{array}{l}\widehat{\rho} \\
\stackrel{8}{0} \\
0 \\
e\end{array}$ & $\begin{array}{l}\text { Oे } \\
\text { Oे. } \\
\text { Oे. }\end{array}$ & $\begin{array}{l}\frac{\infty}{\tilde{\sigma}} \\
\hat{0} \\
\stackrel{e}{e}\end{array}$ \\
\hline 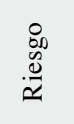 & $\begin{array}{l}\stackrel{\circ}{n} \\
\text { ¿̂. } \\
\text { o. }\end{array}$ & 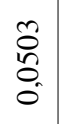 & 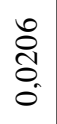 & \begin{tabular}{l}
8 \\
8 \\
8 \\
\hdashline
\end{tabular} & $\begin{array}{l}\stackrel{+}{\sigma} \\
\stackrel{2}{0}\end{array}$ & $\begin{array}{l}\hat{\sigma} \\
0 \\
0\end{array}$ & $\stackrel{\sigma}{\sigma}$ & 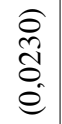 & $\begin{array}{l}\overline{0} \\
\text { ᄋ̆ } \\
0\end{array}$ \\
\hline 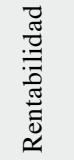 & $\begin{array}{l}\hat{\curvearrowright} \\
\stackrel{\oplus}{e} \\
\stackrel{e}{0}\end{array}$ & $\begin{array}{l}\stackrel{N}{F} \\
\vec{O} \\
0\end{array}$ & $\begin{array}{l}8 \\
8 \\
8 \\
0\end{array}$ & $\begin{array}{l}0 \\
\stackrel{0}{0} \\
\text { Oे } \\
0\end{array}$ & $\begin{array}{l}\widehat{\widehat{े}} \\
\text { ָे } \\
\stackrel{c}{e}\end{array}$ & $\underset{0}{\stackrel{\Delta}{0}}$ & $\begin{array}{l}\widehat{\widehat{\sigma}} \\
\text { } \\
\stackrel{0}{0}\end{array}$ & $\begin{array}{l}\tilde{\infty} \\
\stackrel{\infty}{0} \\
0\end{array}$ & $\frac{\infty}{\stackrel{\varrho}{=}}$ \\
\hline 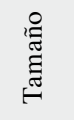 & 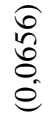 & $\begin{array}{l}8 \\
8 \\
8\end{array}$ & $\begin{array}{l}\stackrel{N}{F} \\
\underset{0}{0} \\
\stackrel{0}{0}\end{array}$ & $\begin{array}{l}\hat{2} \\
\stackrel{\circ}{0} \\
0 \\
0\end{array}$ & $\begin{array}{l}\stackrel{+}{O} \\
\stackrel{0}{0} \\
\stackrel{0}{0}\end{array}$ & $\frac{\overparen{f}}{\stackrel{f}{e}}$ & $\begin{array}{l}\hat{f} \\
\stackrel{\infty}{n} \\
\stackrel{0}{e}\end{array}$ & 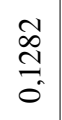 & 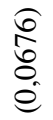 \\
\hline 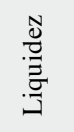 & $\begin{array}{l}8 \\
8 \\
8 \\
0\end{array}$ & 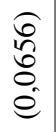 & $\begin{array}{l}\widehat{\curvearrowright} \\
\stackrel{\oplus}{e} \\
\stackrel{e}{e}\end{array}$ & $\begin{array}{l}0 \\
\stackrel{n}{1} \\
0 \\
0 \\
0\end{array}$ & $\begin{array}{l}\stackrel{0}{0} \\
\stackrel{\mathbb{S}}{0} \\
\stackrel{e}{e}\end{array}$ & 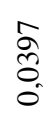 & $\begin{array}{l}\stackrel{\overbrace{}}{\widehat{\sigma}} \\
\stackrel{0}{0}\end{array}$ & 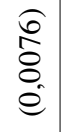 & $\begin{array}{l}\text { } \\
\stackrel{ }{d} \\
\stackrel{e}{e}\end{array}$ \\
\hline 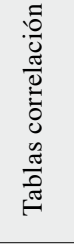 & 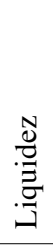 & 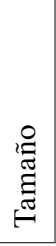 & 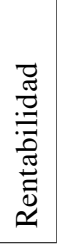 & 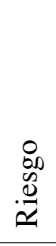 & 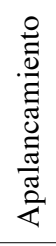 & 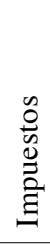 & 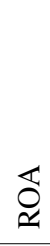 & $\stackrel{\text { II }}{0}$ & 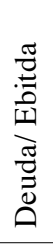 \\
\hline
\end{tabular}


De este análisis se evidenció la alta correlación entre ROE, ROA y apalancamiento, por lo cual se procedió a excluir de la regresión las tres variables eliminando la colinealidad de la información.

\section{Resultados}

Lo primero que se realizó dentro del estudio fue una depuración de la base de datos, eliminado las variables que cuya ratio de pago de dividendos fuera menor a 0 , para normalizar la muestra, lo que llevó a que se pasara de tener 679 datos de entradas, a 434, equivalente a una depuración de 37 empresas (62 empresas en total). Esta depuración se hizo para: i) eliminar posibles efectos contractuales que generalmente limitan el pago de dividendos como los covenants no financieros o las reglamentaciones de empresas públicas; ii) adicionalmente, dentro de la muestra se encontró que las empresas repartían dividendos así tuvieran pérdidas del ejercicio contra sus utilidades retenidas de ejercicios anteriores, o disminución de reservas, lo que llevaba a que se tuvieran ratios de pago de dividendos negativas que distorsionaban el análisis (tabla 7).

Una vez depurada la base, se realizó una regresión multivariada incluyendo todas las variables dependientes enunciadas en el punto de metodología, lo cual arrojó que de las 9 ratios utilizadas en la muestra, tan solo 1 resultó significativa al $95 \%$ de confianza.

Tabla 7: Empresas latinoamericanas (todas la industrias) $\mathrm{N}=434$

\begin{tabular}{|l|c|c|c|c|c|}
\hline \multicolumn{3}{|c|}{ R Cuadrado=0,1556 } & \multicolumn{3}{c|}{ R Cuadrado Adj=0,1397 } \\
\hline \multicolumn{1}{|c|}{ Variables } & Estimación & Error estándar & T Value & P Value & Significancia \\
\hline Intercepto & $-1,592821$ & 2.194200 & -0.726000 & 0.468000 & No significativa \\
\hline Liquidez & $-0,039505$ & 0,075102 & $-0,536000$ & 0,599000 & No significativa \\
\hline Tamaño & 0,142039 & 0,193318 & 0,735000 & 0,463000 & No significativa \\
\hline Rentabilidad & $-0,199557$ & 1,746150 & $-0,114000$ & 0,909000 & No significativa \\
\hline Riesgo & 0,003423 & 0,004192 & 8,165000 & $3,69 E-15$ & $0,1 \%$ \\
\hline Deuda/ Ebitda & 0,068385 & 0,107963 & 0,633000 & 0,527000 & No significativa \\
\hline Impuestos & 4,156367 & 4,537947 & 0,916000 & 0,360000 & No significativa \\
\hline País & 0,206546 & 0,170186 & 1,214000 & 0,226000 & No significativa \\
\hline Industria & $-0,062585$ & 0,075861 & $-0,825000$ & 0,410000 & No significativa \\
\hline
\end{tabular}

Fuente: elaboración propia. 
Asimismo, se observó que la variable con mayor significancia es la percepción del riesgo que, sumada a un bajo nivel de predictibilidad del modelo (14\%) se considera baja (un modelo relevante debería explicar el $70 \%$ ), lo cual lleva a que el modelo no sea relevante para la determinación de la tasa de pago de dividendos.

Resaltamos que este modelo explicativo tiene menores niveles de predictibilidad que lo evidenciado en el trabajo de Mehta (2012), donde el modelo explicaba el $41,6 \%$ del pago de dividendos, pero mantenía niveles de predictibilidad similares a los encontrados por Amarjit, Nahum y Tibrewala (2010) cuyo modelo predecía el $15,2 \%$ del pago de dividendos.

Uno de los resultados más llamativos fue que existe una relación positiva entre el apalancamiento (deuda/Ebitda) y el pago de dividendos. Del resultado de esta variable puede inferirse que a mayores niveles de endeudamiento de la entidad mayor será la tasa de reparto de dividendos, contrario a lo planteado por Mehta (2012) y por Amarjit, Nahum y Tibrewala (2010). En este sentido, puede concluirse que dado que los accionistas de una firma tienen mayores niveles de riesgo entre mayor sea su nivel de apalancamiento (en caso de liquidación primero se paga la deuda), las firmas tienden a compensarlos a través de mayores dividendos pagados, lo que aumenta la tasa de retorno de las entidades.

Por otro lado, se encontró una relación negativa entre la rentabilidad y el pago de dividendos, contrario a lo planteado en todas las teorías vistas (Amarjit, Nahum y Tibrewala, 2010; Uwigbe, Jafaru y Anijesushola, 2012; Mehta, 2012; Cristea y Cristea, 2017). Este fenómeno puede ser explicado por el precepto explicado por Fisher (1976), donde se señala que los administradores buscan mantener estable un pago de dividendos a través del tiempo (valor nominal constante) más que mantener una tasa de reparto de dividendos estable. En línea con lo anterior, puede inferirse que cuando las empresas tienen menores niveles de rentabilidad para sus accionistas tienden a compensarlos a través de una mayor tasa de reparto de dividendos buscando mantener un dividendo estable en el tiempo, lo que elimina la volatilidad que existe en su retorno.

Estos factores analizados nos muestran que el dividendo sirve como una forma de responder al riesgo que asumen los accionistas y que, a medida que este aumente (ya sea porque la percepción aumentó o porque la entidad mantiene un estructura de capital más riesgosa) el pago de dividendos tiende a incrementarse, por lo cual se puede concluir que la ratio de dividendos sirve como una señal para los diferentes actores del mercado que buscan mantener altas remuneraciones en efectivo para sus inversiones de alto riesgo. 
Finalmente, notamos que las variables dummy utilizadas para catalogar el país y la industria no muestran ninguna relevancia en la política de dividendos, contrario a lo que se planteó en los trabajos de Amarjit, Nahum y Tibrewala (2010) y Glen, Karmokolias, Miller y Shah (1995), donde se menciona que dependiendo del país y la industria en la que participe tienen una influencia en la política de dividendos de la firma.

A pesar de lo mencionado en el párrafo anterior, dado el bajo nivel de predictibilidad del modelo, se realizó una segmentación de la muestra por industria para ver cómo se comportan individualmente cada una de estas y cuáles son los determinantes de la política de dividendos específicos para cada sector económico analizado. Sabemos que al segmentar la muestra se sacrifica $\mathrm{N}$ y la relevancia de los hallazgos, pero este ejercicio se realizó a fin de establecer si existen algunos determinantes en la política de dividendos.

Aerolíneas ( $\mathrm{N}=17)$ : al realizar el análisis sobre esta industria encontramos que la regresión explica el $7 \%$ del pago de dividendos, siendo las variables de riesgo y tamaño las más significativas para la muestra. En este sentido, se evidenció que se cumple lo planteado por Amarjit, Nahum y Tibrewala (2010) donde dependiendo de la industria analizada, los determinantes de la política de dividendos varían, lo que permite concluir que cada industria tiene determinantes específicos para la escogencia de la política de distribución de utilidades. Asimismo, se observó que, contrario a lo planteado por Mehta (2012); Amarjit, Nahum y Tibrewala (2010) y Cristea y Cristea (2017), las empresas aéreas mantienen una relación negativa entre su tamaño y su tasa de reparto de dividendos, lo que muestra que empresas de menor tamaño compensan su mayor riesgo a través de mayores tasas de dividendos. Finalmente, en línea con lo observado para todo el mercado, la percepción del riesgo y el apalancamiento mantienen una relación positiva con el pago de dividendos, reforzando lo que se planteó en el punto anterior, donde vemos la relevancia del dividendo como una forma de comunicar mensajes al mercado, el cual termina siendo el medio por el cual la administración da un parte de tranquilidad a los actores que intervienen en el mercado de capitales.

De igual manera, se evidencia que los planteamientos realizados sobre los indicadores de liquidez, impuestos, deuda/Ebitda se encuentran alineados con lo planteado por las diferentes teorías observadas a lo largo de la presentación, con una relación negativa frente al pago de dividendos. Por su parte, la rentabilidad (EBIT/Activos) mantiene una relación positiva con el pago de dividendos en donde mayor sea la generación operativa de la entidad (EBIT) mayor será el 
pago de dividendos alineado con lo planteado por Amarjit, Nahum y Tibrewala (2010); Mehta (2012 ) y Cristea y Cristea (2017).

A pesar de los resultados encontrados, dada la limitada información de la compañía (tan solo 17 observaciones), puede que las conclusiones alcanzadas para la industria no sean significativas a pesar de que se contó con información de los principales jugadores del mercado latinoamericano.

En la tabla 8 se presentan los resultados obtenidos en la regresión realizada.

Tabla 8: Empresas latinoamericanas (Aerolíneas) $\mathrm{N}=17$

\begin{tabular}{|l|c|c|c|c|c|}
\hline \multicolumn{3}{|c|}{ R Cuadrado $=0,98782$} & \multicolumn{3}{c|}{ R Cuadrado Adj=0,9651 } \\
\hline \multicolumn{1}{|c|}{ Variables } & Estimación & Error estándar & T Value & P Value & Significancia (\%) \\
\hline Intercepto & 69,911620 & 67,766950 & 2,955000 & 0,018300 & 1,0 \\
\hline Liquidez & $-19,930360$ & 7,087870 & $-1,589000$ & 0,150800 & 5,0 \\
\hline Tamaño & $-8,350990$ & 7,758660 & $-2,989000$ & 0,017400 & $0,1 \%$ \\
\hline Rentabilidad & 41,969710 & 0,037180 & 13,020000 & 0,253300 & No significativa \\
\hline Riesgo & 0,539010 & 0,037180 & 13,020000 & $1,15 \mathrm{E}-06$ & 0,1 \\
\hline Deuda/ Ebitda & $-0,517140$ & 2,024550 & 2,188000 & 0,006010 & No significativa \\
\hline Impuestos & 86,423790 & 21,148830 & $-0,554000$ & 0,594700 & 1,0 \\
\hline
\end{tabular}

Fuente: elaboración propia.

Oil \& Gas ( $\mathrm{N}=25)$ : la siguiente industria analizada fue la de petróleo y gas que, al igual que en la industria de aerolíneas, mantiene un número bajo de observaciones, por lo cual los resultados no son significativos para un estudio. A pesar de lo anterior, notamos que la predictibilidad del modelo alcanzó $37 \%$, donde la percepción del riesgo resultó ser la variable que más explica el reparto de dividendos de las firmas de esta industria. Adicionalmente, notamos la significancia que tienen los impuestos y la rentabilidad frente a la tasa de reparto de dividendos (5\% de significancia). En relación con los impuestos, estos mantienen una relación positiva con el pago de dividendos en línea lo planteado por Mehta (2012). Por su parte, la rentabilidad mantiene un comportamiento negativo frente al pago de dividendos, en línea con lo evidenciado a lo largo del estudio, donde menores niveles de rentabilidad derivan en mayores niveles de dividendos. También se demostró que, de acuerdo con lo observado en las demás industrias, la percepción del riesgo nos demuestra nuevamente que 
el dividendo es una respuesta de la administración al mercado. Finalmente, se destaca que bajo este modelo vemos la relevancia del pago de impuestos para la determinación de la política de dividendos y que se alinea con la teoría planteada por Fisher (1976). A continuación, se presentan los resultados de la regresión realizada (tabla 9).

Tabla 9: Empresas latinoamericanas (Oil \& Gas) $\mathrm{N}=25$

\begin{tabular}{|l|c|c|c|c|c|}
\hline \multicolumn{3}{|c|}{ R Cuadrado=0,5369 } & \multicolumn{3}{c|}{ R Cuadrado Adj=0,3735 } \\
\hline \multicolumn{1}{|c|}{ Variables } & Estimación & Error estándar & T Value & P Value & Significancia (\%) \\
\hline Intercepto & 1,705200 & 1,267771 & 1,345000 & 0,196280 & No significativa \\
\hline Liquidez & $-0,333556$ & 0,469344 & $-0,711000$ & 0,486920 & No significativa \\
\hline Tamaño & $-0,026869$ & 0,070475 & $-0,381000$ & 0,707740 & No significativa \\
\hline Rentabilidad & $-4,139036$ & 1,863506 & $-2,221000$ & 0,940220 & 5,0 \\
\hline Riesgo & 0,006053 & 0,001731 & 3,496000 & 2,77 E-03 & 1,0 \\
\hline Deuda/Ebitda & $-0,160469$ & 0,110949 & $-1,446000$ & 0,166270 & No significativa \\
\hline Impuestos & 9,375087 & 3,528311 & 2,657000 & 0,016590 & 5,0 \\
\hline
\end{tabular}

Fuente: elaboración propia.

Alimentos y Bebidas $(\mathrm{N}=70)$ : bajo el modelo realizado, se observó que las variables de tamaño y riesgo explican el $74 \%$ del pago de dividendos de las firmas. Bajo este modelo se tiene un nivel de significancia alto de la variable de riesgo, alineado con lo que se ha observado a lo largo de la aproximación empírica realizada. De acuerdo con lo que se ha visto, se destaca que la percepción de riesgo que se tiene de la firma es uno de los mayores determinantes del pago. Por otro lado, se encontró una relación negativa entre el tamaño de la empresa y el pago de dividendos, que en línea con lo que se ha planteado a lo largo del análisis de resultados lleva a pensar que, dado que las empresas de menor tamaño representan un mayor nivel de riesgo para los inversionistas, la administración tiende a compensar esta mayor exposición a través de una mayor tasa de dividendos, recalcando en la relevancia que toma el pago de dividendos como una forma de transmisión de información al mercado. A continuación, se presentan los resultados del modelo (tabla 10). 
Tabla 10: Empresas latinoamericanas (Alimentos y Bebidas) $\mathrm{N}=70$

\begin{tabular}{|l|c|c|c|c|c|}
\hline \multicolumn{3}{|c|}{ R Cuadrado $=0,7652$} & \multicolumn{3}{c|}{ R Cuadrado Adj=0,7428 } \\
\hline \multicolumn{1}{|c|}{ Variables } & Estimación & Error estándar & T Value & P Value & Significancia (\%) \\
\hline Intercepto & 1,462559 & 0,672928 & 2,173000 & 0,033510 & 5,0 \\
\hline Liquidez & $-0,110050$ & 0,155186 & $-0,709000$ & 0,480850 & No significativa \\
\hline Tamaño & $-0,184179$ & 0,061518 & $-2,994000$ & 0,003930 & 1,0 \\
\hline Rentabilidad & 3,716764 & 2,497565 & 1,488000 & 0,141790 & No significativa \\
\hline Riesgo & 0,015160 & 0,001135 & 13,353000 & $2,00 \mathrm{E}-16$ & 0,1 \\
\hline Deuda/Ebitda & 0,090310 & 0,056811 & 1,590000 & 0,116920 & No significativa \\
\hline Impuestos & $-1,444702$ & 1,740132 & $-0,830000$ & 0,409550 & No significativa \\
\hline
\end{tabular}

Fuente: elaboración propia.

Retail ( $\mathrm{N}=53)$ : cuando se llevó a cabo el análisis de las empresas retailers del mercado latino, se encontró que el modelo explicaba cerca del $92 \%$ del pago de dividendos de dichas empresas. En este sentido, se encontró una significancia (al 95\%) de las variables de liquidez, tamaño y riesgo. Otro hallazgo fue que existe una relación positiva entre la liquidez, el tamaño y el riesgo, como lo plantearon Amarjit, Nahum y Tibrewala (2010), Mehta (2012) y Cristea y Cristea (2017), donde los dividendos se benefician de altos niveles de liquidez (disponibilidad de recursos para pagarlos), y en donde las empresas con más riesgos y las de mayor tamaño mantienen un mayor pago de dividendos.

A continuación, se presentan los diferentes resultados del modelo corrido para las empresas de retail en América Latina (tabla 11).

Tabla 11: Empresas latinoamericanas (Retail) $\mathrm{N}=53$

\begin{tabular}{|l|c|c|c|c|c|}
\hline \multicolumn{3}{|c|}{ R Cuadrado $=0,9308$} & \multicolumn{3}{c|}{ R Cuadrado Adj=0,9217 } \\
\hline \multicolumn{1}{|c|}{ Variables } & Estimación & Error estándar & T Value & P Value & Significancia (\%) \\
\hline Intercepto & $-0,836912$ & 0,441887 & $-1,894000$ & 0,006450 & 10,0 \\
\hline Liquidez & 0,007986 & 0,003856 & 2,071000 & 0,044000 & $5,0 \%$ \\
\hline Tamaño & 0,095959 & 0,041340 & 2,321000 & 0,024800 & $5,0 \%$ \\
\hline Rentabilidad & 0,402832 & 0,845838 & 0,476000 & 0,636100 & No Significativa \\
\hline
\end{tabular}




\begin{tabular}{|l|c|c|c|c|c|}
\hline \multicolumn{3}{|c|}{ R Cuadrado $=0,9308$} & \multicolumn{3}{c|}{ R Cuadrado Adj=0,9217 } \\
\hline \multicolumn{1}{|c|}{ Variables } & Estimación & Error estándar & T Value & P Value & Significancia (\%) \\
\hline Riesgo & 0,007065 & 0,000306 & 23,100000 & $2,00 \mathrm{E}-16$ & $1,0 \%$ \\
\hline Deuda/Ebitda & 0,020522 & 0,013273 & 1,546000 & 0,128900 & No Significativa \\
\hline Impuestos & $-0,151472$ & 0,771920 & $-0,196000$ & 0,845300 & No Significativa \\
\hline
\end{tabular}

Fuente: elaboración propia.

Industriales $(\mathrm{N}=80)$ : cuando se realizó el ejercicio para las empresas industriales se obtuvo un modelo donde la rentabilidad y el riesgo son relevantes para la determinación de la política de dividendos. A pesar de lo anterior, estas variables solo explican el $34 \%$ del comportamiento del indicador de pago de dividendos. en este sentido, encontramos que la rentabilidad y la percepción de riesgo mantienen una relación positiva con el pago de dividendos, en línea con lo planteado por los diferentes autores estudiados a lo largo de este artículo. En la tabla 12 se presentan los resultados del modelo.

Tabla 12: Empresas latinoamericanas (Actividad Industrial) $\mathrm{N}=80$

\begin{tabular}{|l|c|c|c|c|c|}
\hline \multicolumn{3}{|c|}{ R Cuadrado=0,4046 } & \multicolumn{3}{c|}{ R Cuadrado Adj=0,3375 } \\
\hline \multicolumn{1}{|c|}{ Variables } & Estimación & Error estándar & T Value & P Value & Significancia (\%) \\
\hline Intercepto & $-0,411970$ & 0,905926 & $-0,455000$ & 0,650640 & No Significativa \\
\hline Liquidez & $-0,693290$ & 0,120489 & $-0,575000$ & 0,566730 & No Significativa \\
\hline Tamaño & 0,126660 & 0,120469 & 0,140000 & 0,888890 & No Significativa \\
\hline Rentabilidad & 4,303287 & 0,090344 & 3,040000 & 0,003280 & $1,0 \%$ \\
\hline Riesgo & 0,002794 & 0,004911 & 5,689000 & $2,48 \mathrm{E}-07$ & $0,1 \%$ \\
\hline Deuda/Ebitda & $-0,068066$ & 0,069944 & $-0,973000$ & 0,033369 & No Significativa \\
\hline Impuestos & 1,477048 & 2,034871 & 0,726000 & 0,470240 & No Significativa \\
\hline
\end{tabular}

Fuente: elaboración propia.

Las demás industrias no mostraron altos niveles de significancia en sus variables independientes y arrojaron niveles de predictibilidad bajos, por lo cual no serán explicadas a detalle en el estudio.

Después de haber segmentado la muestra por industrias, se pasó a observar cómo era el comportamiento del pago de dividendos si se segmentara la muestra 
por países. Con esta investigación se pretende identificar si los determinantes de la política de dividendos varían de un país a otro en línea con lo que se ha presentado a lo largo del estudio y, principalmente, en el trabajo de Glen, Karmokolias, Miller y Shah (1995), donde vemos que el ambiente macroeconómico, político y coyuntural de los países afecta la política de dividendos de las empresas localizadas geográficamente en zonas diferentes. ${ }^{7}$

Colombia $(\mathrm{N}=101)$ : al correr la regresión lineal segmentando por países, el país en donde el modelo presenta un mayor grado de certeza es Colombia, allí el modelo explica el $40 \%$ de la ratio de pago de dividendos, cuya variable significativa al $95 \%$ de confianza fue el riesgo. En este orden de ideas, se encontró una relación positiva entre dicha variable y la tasa de reparto de dividendos de la firma, lo que nos muestra, nuevamente, la relación que tiene el pago de dividendos con el riesgo de una compañía, en donde a mayor riesgo (mayor percepción de riesgo) se tendrá un mayor pago de dividendos. En la tabla 13 se presentan los resultados obtenidos de la regresión.

Tabla 13: Empresas colombianas (todas las industrias)

\begin{tabular}{|l|c|c|c|c|c|}
\hline \multicolumn{3}{|c|}{ R Cuadrado $=0,4225$} & \multicolumn{3}{c|}{ R Cuadrado Adj=0,3921 } \\
\hline \multicolumn{1}{|c|}{ Variables } & Estimación & Error estándar & T Value & P Value & Significancia (\%) \\
\hline Intercepto & $-0,650600$ & 3,938700 & $-0,166000$ & 0,869000 & No significativa \\
\hline Liquidez & $-0,042750$ & 0,120990 & 0,353000 & 0,735000 & No significativa \\
\hline Tamaño & $-0,368590$ & 0,500340 & $-0,737000$ & 0,463000 & No significativa \\
\hline Rentabilidad & 1,445060 & 5,056600 & 0,286000 & 0,776000 & No significativa \\
\hline Riesgo & 0,227520 & 0,029160 & 7,801000 & $7,88 \mathrm{E}-12$ & $0,1 \%$ \\
\hline Deuda/Ebitda & 0,359140 & 0,347570 & 1,033000 & 0,304000 & No significativa \\
\hline
\end{tabular}

Fuente: elaboración propia.

Brasil ( $\mathrm{N}=103)$ : en el caso de Brasil, tan solo la variable de riesgo resultó significativa para el modelo de regresión, lo que lleva a la baja predictibilidad del modelo, el cual predice cerca del $20 \%$ de la política de pago de dividendos.

7 Dentro de la segmentación por países se eliminó de la muestra la variable de tasa impositiva cobrada a los dividendos, ya que esta no presentaba variaciones para las empresas que pertenecen a un país, dado que las tasas de impuestos cobrados a los dividendos son iguales para todos los sectores de la economía del país. 
Dados los resultados obtenidos, y que solo una de las variables resultó significativa para el modelo, deberá realizarse un análisis más profundo al caso de las empresas brasileñas para encontrar cuáles son los principales motivos que llevan a que estas empresas paguen dividendos. En la tabla 14 se presentan los resultados obtenidos en la regresión.

Tabla 14: Empresas brasileñas (todas las industrias) $\mathrm{N}=103$

\begin{tabular}{|l|c|c|c|c|c|}
\hline \multicolumn{3}{|c|}{ R Cuadrado=0,2425 } & \multicolumn{3}{c|}{ R Cuadrado Adj=0,2035 } \\
\hline \multicolumn{1}{|c|}{ Variables } & Estimación & Error estándar & T Value & P Value & Significancia (\%) \\
\hline Intercepto & $-3,789576$ & 3,792561 & 1,508000 & 0,320000 & No significativa \\
\hline Liquidez & $-0,426974$ & 0,575750 & 0,550000 & 0,460000 & No significativa \\
\hline Tamaño & 0,527071 & 0,349518 & $-0,742000$ & 0,135000 & No significativa \\
\hline Rentabilidad & 2,683420 & 4,878670 & 0,550000 & 0,584000 & No significativa \\
\hline Riesgo & 0,027629 & 0,005627 & 4,910000 & $3,69 \mathrm{E}-06$ & $0,1 \%$ \\
\hline Deuda/Ebitda & $-0,216250$ & 0,252147 & $-0,858000$ & 0,393000 & No significativa \\
\hline
\end{tabular}

Fuente: elaboración propia.

México $(\mathrm{N}=99)$ : en el caso de las empresas mexicanas notamos que el modelo solo explicaba el $27 \%$ de la política de dividendos, más puntualmente, la percepción del riesgo explicaba el comportamiento del pago de dividendos, al ser la única variable significativa encontrada en la regresión (significancia del $1 \%$ ). En la tabla 15 se presentan los resultados obtenidos.

Tabla 15: Empresas mexicanas (todas las industrias) $\mathrm{N}=99$

\begin{tabular}{|l|c|c|c|c|c|}
\hline \multicolumn{3}{|c|}{ R Cuadrado=0,3059 } & \multicolumn{3}{c|}{ R Cuadrado Adj=0,2685 } \\
\hline \multicolumn{1}{|c|}{ Variables } & Estimación & Error estándar & T Value & P Value & Significancia (\%) \\
\hline Intercepto & $-0,546703$ & 0,519140 & $-0,924000$ & 0,358000 & No Significativa \\
\hline Liquidez & 0,104993 & 0,114511 & 0,916000 & 0,362000 & No Significativa \\
\hline Tamaño & 0,049305 & 0,049372 & 0,999000 & 0,321000 & No Significativa \\
\hline Rentabilidad & 0,317720 & 0,609755 & 0,521000 & 0,606000 & No Significativa \\
\hline Riesgo & 0,019058 & 0,003037 & 6,276000 & $1,09 \mathrm{e}-08$ & $0,1 \%$ \\
\hline Deuda/Ebitda & 0,040593 & 0,070536 & 0,575000 & 0,566000 & No Significativa \\
\hline
\end{tabular}

Fuente: elaboración propia. 
Finalmente, para las empresas chilenas y panameñas las variables resultaron ser no significativas a lo largo de toda la muestra. En el caso de Perú, pese a que el modelo predecía el pago de dividendos en un $69 \%$, tan solo se contaba con 5 datos de entrada por lo cual los resultados estaban sesgados y no eran óptimos para realizar un análisis adecuado.

\section{Conclusiones}

Después de revisar los resultados del modelo se encontraron ciertos patrones que tienen las entidades del mercado en Latinoamérica y que nos ayudan a responder la pregunta: ¿cuáles son los determinantes de la política de dividendos en el mercado latinoamericano?

1. Al realizar el análisis de datos de todo el mercado latinoamericano se encontró que la política de dividendos de las firmas se explica por ciertas variables que presentan, por lo cual se puede inferir que tal como se revisó a lo largo del documento, los dividendos son relevantes para la determinación de valor de una entidad. Asimismo, se evidenció que dependiendo de la región geográfica y de la industria los determinantes de la política de dividendos pueden variar en línea con lo que plantearon Glen, Karmokolias, Miller y Shah (1995); Amarjit, Nahum y Tibrewala (2010).

Dentro de los resultados generales (base que incluye todos los países y todas las industrias) se observó que el modelo era predictivo tan solo en un $14 \%$ (R2), lo que constituye una baja predictibilidad frente a modelos convencionales pero que se asemeja a los niveles observados en el trabajo de Amarjit, Nahum y Tibrewala (2010). Por su parte, la variable más significativa del modelo es la percepción de riesgo medida como precio de la acción sobre utilidad por acción.

A partir de este indicador vemos que existe una relación positiva entre el apalancamiento, la percepción de riesgo y la ratio de pago de dividendos (la ratio de dividendos aumenta cuando estas variables aumentan). Al analizar los resultados se encuentra que a medida que el $\mathrm{P} / \mathrm{E}$ aumenta (riesgo de ingresos del accionista disminuye) la ratio pagada de dividendos se incrementa. Esto va de la mano con lo que plantea Fisher (1976), donde las empresas prefieren mantener un pago de dividendo estable en el tiempo (valor nominal) frente a una ratio de repartición de dividendos sobre utilidades estable, ya que los 
dividendos se convierten en una forma de transmisión de información al mercado por parte de la administración. Esto permite concluir que el dividendo es una señal muy relevante para el mercado y que afecta directamente el valor de la firma.

2. En la muestra general del mercado encontramos que los impuestos no son relevantes para la determinación de la política de dividendos tal como lo plantea Bernheim (1990). Adicionalmente, puede llegar inferirse, tal como lo señaló dicho autor, que las entidades prefieren mantener sus niveles de dividendos sin importar el comportamiento de la tasa impositiva, ya que estos están sirviendo como un input de información en el mercado (basado en lo explicado en el punto 1). Cabe resaltar que para las empresas del sector específico de Oil \& Gas, esta variable toma gran relevancia dadas las fuertes inversiones que realizan los accionistas de las compañías para poder llevar a cabo el plan de inversiones de capital que la industria demanda. En este sentido, se puede inferir que, para esta industria en específico, el valor del impuesto cobrado a los dividendos sí es una variable determinante a la hora de establecer la política de repago de estos.

3. En línea con lo observado por Mehta (2012), una de las variables más significativas para la explicación de la política de dividendos es la percepción de riesgo (nivel de significancia del $0,1 \%$ en promedio). En este sentido, vemos que entre mayor sea el $\mathrm{P} / \mathrm{E}$ (menor riesgo del inversor), mayor será el pago de dividendos, lo cual reafirma lo visto a lo largo del trabajo donde los dividendos funcionan como una fuente de información al mercado, ya que transmiten a los accionistas una visión del futuro del comportamiento del pago de dividendos tal como lo explicaron Fisher (1976), Bernheim (1990), Modigliani y Miller (1963), Miller y Rock (1985), Cristea y Cristea (2017).

4. Al segmentar por industrias y países, los niveles de predictibilidad del modelo incrementaron. En este sentido se observó, también, que la relevancia de los determinantes de la política de dividendos cambiaba dependiendo de la industria y el país de la firma, según lo planteado por Glen, Karmokolias, Miller y Shah (1995) y por Amarjit, Nahum y Tibrewala (2010), donde las condiciones específicas de industria y país terminan siendo relevantes para la determinación de la política de dividendos.

5. En Colombia, el determinante que explica el $40 \%$ de la tasa de reparto de dividendos es el riesgo, con una significancia del 0,1\%. Al igual que lo visto en el análisis de datos de toda la muestra, encontramos que a medida que 
incrementa el P/E y la percepción de riesgo disminuye, la firma incrementa la ratio de dividendos, lo que los convierte en una señal de mercado sobre el estado actual de la entidad. Por su parte, la rentabilidad mantiene una relación positiva con la ratio de pago de dividendos, de acuerdo con lo planteado por Mehta (2012); Amarjit, Nahum y Tibrewala (2010), dado que entre mayor sea la rentabilidad que generen los activos, los inversionistas esperar mejores niveles de remuneración.

6. La regresión corrida sobre la industria retail de la región mantiene mayores niveles de predictibilidad en el mercado latinoamericano (92\%). En esta industria notamos que la liquidez, el tamaño y la percepción del riesgo mantienen una relación positiva con el pago de dividendos, en línea con lo planteado por Fisher (1976); Uwigbe, Jafaru y Anijesushola (2012); Cristea y Cristea (2017); Amarjit, Nahum y Tibrewala (2010) y Mehta (2012). Se destaca que el comportamiento encontrado en esta regresión fue el que más se parece al encontrado en los trabajos revisados en este artículo.

7. En concordancia con lo planteado por Amarjit, Nahum y Tibrewala (2010) y Glen, Karmokolias, Miller y Shah (1995), el comportamiento de la política de dividendos varía dependiendo de la industria a la que pertenezca la empresa o la localización geográfica en donde esta se encuentre ubicada. Este análisis nos permite ver que no solo existen factores específicos de una compañía (estructura de capital) que determinan su política de dividendos, sino que, a su vez, factores externos/coyunturales afectarán el monto de los dividendos por repartir.

8. Al ser la precepción de riesgo la variable más significativa para la determinación de la política de dividendos de las empresas latinoamericanas, se puede afirmar, entonces, que estos no son irrelevantes para los inversionistas, contrario a lo planteado por Modigliani y Miller (1961). Asimismo, podría afirmarse que los dividendos son buenos para la valoración de una firma ya que sirven como una señal para el mercado sobre la estabilidad de la entidad, como lo plantearon Miller y Rock (1985) y, por ende, sí existen determinantes específicos de una firma que llevan a explicar la política de dividendos.

9. Finalmente, a partir de los resultados obtenidos en este trabajo se abre la oportunidad de profundizar en investigaciones que permitan ver con mayor detenimiento los determinantes de la política de dividendos en Latinoamérica. Dentro de las líneas de investigación para llevar a cabo se encuentran: 
i) Dada la limitación de la muestra obtenida, donde la mayoría de las empresas son grandes corporaciones (listadas en Bolsa), se debe realizar una investigación enfocada en empresas con menor tamaño (pequeñas y medianas) de las industrias latinoamericanas para saber si los determinantes de la política de dividendos hallados para las empresas listadas aplican en las empresas de menor escala.

ii) Dado que los determinantes de la política de dividendos variaban dependiendo de la localización geográfica de las empresas, se debe profundizar en la relación que tienen variables macroeconómicas sobre el pago de la política de dividendos, para determinar si estas variables, sumadas a las características puntuales de la compañía, explican de mejor manera el comportamiento del pago de dividendos en las firmas.

iii) En línea con lo planteado por Fisher (1976), las administraciones buscan que el pago de sus dividendos sea menos volátil, por lo cual debe profundizarse en si las empresas mantienen sus niveles de pago de dividendos a pesar de que sus condiciones financieras cambien, desarrollando un estudio que mire la volatilidad del pago (nominal del dividendo) con los principales determinantes de la política de dividendos hallados en esta investigación.

iv) Al ser el pago de dividendos una señal de mercado (como lo hemos visto en los puntos anteriores), se debe desarrollar una investigación que indague sobre cuál es la ratio que tiene la gerencia para determinar las tasas de pago de dividendos de una firma, en línea con lo planteado por Azouzi y Jarboui (2012). Desde ese punto de vista, no solo se tendría un entendimiento de que a mayor riesgo la tasa de dividendos aumentará, sino que se entenderá la motivación que dicho aumento de riesgo genera en la administración, que es la principal encargada de determinar la política de dividendos de la firma.

v) Si bien la muestra se enfocó en estudiar un periodo de tiempo de 6 años (dada la disponibilidad de la información), se debe ampliar la base de datos para abarcar un mayor lapso de tiempo donde se tenga un mayor número de periodos y de tendencias macroeconómicas con el fin de poder evaluar cómo se comporta el pago de dividendos en ciclos económicos menos favorables. 


\section{Referencias}

Allen, F., Myers, S. C. y Brealey, R. A. (2010). Principio de finanzas corporativas (9 ed.). McGraw Hill.

Amarjit, G., Nahum, B. y Tibrewala, R. (2010). Determinants of dividend payout ratios: Evidence from United States. The Open Bussines Journal, 3, 8-14.

Azouzi, M. A. y Jarboui, A. (2012). CEO Emotional bias and dividend policy. Business and Economic Horizons, 7(1), 1-18.

Bernheim, D. (1990). Tax policy an the dividend Puzzle. Working Paper, 3434, National Bureu of Economic Reseach.

Cristea, C. y Cristea, M. (2017). Determinants of corporate dividend policy: Evidence from romanian listed companies. Annual Session of Scientific Papers IMT ORADEA. EDP Sciences.

Damodaran, A. (2014). Applied Corporate Finance (4 ed.). John Wiley \& Sons.

Fisher, B. (1976). The dividend Puzzle. The Journal of Portfolio Management, 5-8.

Glen, J., Karmokolias, Y., Miller, R. R. y Shah, S. (1995). Dividend policy and behavior in emerging markets. To pay or not to pay. IFC Discusión paper 26.

Holder, M. E., Langrehr, F. W. y Hexter, J. L. (1998). Dividend policy determinants: An investigation of the influence of stakeholders theory. Financial Management, 27(3), 73-82.

Juma'h, A. H. y Oliveras Pacheco, C. J. (2007). The economical and behavioral determinants of cash dividends policy. Forum Empresarial, 12 (2), 54-75.

Lintner, J. (1956). Distribution of incomes of corporations among dividens, retained earnigs and taxes. AM Econ Rev, 97-113.

Lozano, M. B., Miguel, A. d. y Pindado, J. (2002). Papel de la política de dividendos en las empresas reguladas. Investigaciones Económicas, XXVI. 
Mehta,A. (2012). An empirical analysis of determinants of dividend policy- Evidence from UAE companies. Global Review of Accounting and Finance, 3, 18-31.

Miller, M. H. y Rock, K. (1985). Dividend policy under asymetric information. The Journal of Finance, 40 (4), 1031-1051.

Modigliani, F. y Miller, M. H. (1961). Dividend policy, growth, and the valuation of shares. The Journal of Business, 34(4), 411-433.

Modigliani, F. y Miller, M. H. (1963). Corporate income taxes and the cost of capital: A correction. The American Economic Review, 53 (3), 433-443.

Obradovich, J. y Gill, A. (2013, November 1). Corporate governance, institutional ownership, and the decision to pay the amount of dividend: Evidence from USA. Scholars Crossing, The Institutional Repository of Liberty University. Recuperado de: https://digitalcommons.liberty.edu/busi_fac_pubs/26/

Ross, S. A., Westerfield, R. W. y Jordan, B. D. (2014). Fundamentos de finanzas corporativas (10 ed.). McGraw Hill Education.

Thanwarat, S. (2012). Impacts of dividend announcement on stock return. ProcediaSocial and Behavioral Sciences, 40, 721-725.

Uwigbe, U., Jafaru, J. y Anijesushola, A. (2012). Dividend policy and firm performance: A Study of listed firms in Nigeria. Accounting and Management Information Systems. 11 (3), 442-454.

Vera, A. M. (2007). Política de dividendos, riesgo, endeudamiento y estructura de propiedad: un análisis para el mercado español. El Trimestre Económico, 74 (4), 929-960. 